This is an Accepted Manuscript of an article published by Taylor \& Francis in Electric Power Components and Systems on 21/03/2018, available online: http://www.tandfonline.com/10.1080/15325008.2018.1431818 


\title{
Decoupling Controller Design and Controllable Regions Analysis for the Space Vector Modulated Matrix Converter-Unified Power Flow Controller in Transmission Systems
}

\author{
Jianwei Zhang ${ }^{1 *}$, David G. Dorrell ${ }^{2}, \mathrm{Li} \mathrm{Li}^{1}$, Youguang Guo ${ }^{1}$ \\ ${ }^{1}$ Faculty of Engineering and IT, University of Technology Sydney, 15 Broadway, Sydney, Australia \\ ${ }^{2}$ Howard College Campus, University of KwaZulu-Natal, Durban, South Africa \\ *Jianwei.Zhang@uts.edu.au
}

\begin{abstract}
The FACTS devices are essential components of the transmission system to enhance the controllability and elevate the transfer capacity of the network. The unified power flow controller is known as the most versatile device in the FACTS family. This work studies a distinctive UPFC structure based on the direct matrix converter to regulate the active and reactive power in a transmission system. In contrast to the conventional UPFC, there is no requirement for a bulky energy storage element in this structure. This results in various benefits including: decreased system volume, improved efficiency, prolonged lifetime, reduced maintenance and removal of the DC-link control. The full power controllable regions are analyzed and graphically obtained for the MC-UPFC, which facilitates the selection of proper UPFC ratings. The working principles and a model of the MC-UPFC are put forward and discussed, followed by explanations of direct space vector modulation (SVM) for this application. Based on the SVM modulation scheme, PID controllers are developed to control power flows in a double-line transmission system. In addition, decoupling controllers are derived by feeding back the coupling components into controllers. The numerical simulation results for a double-line transmission system corroborate the feasibility and effectiveness of the proposition.
\end{abstract}

Keywords: Power Flow Controller, Matrix Converter, FACTS, UPFC, Decoupling Control, Transmission

\section{Introduction}

Flexible alternating current transmission systems (FACTS) technologies are able to control power flow efficiently, enhance system reliability, mitigate congestion and increase transmission capacity. This can alleviate the problem of continuously increasing electricity demand and provide potential solutions to multi-objective problems in modern power industries [1,2]. The unified power flow controller (UPFC) [3] uses power electronic technology to control transmission system parameters, such as voltage amplitude, 
phase angle and line equivalent impedance, simultaneously or selectively. It has been recognized as the most versatile one among FACTS devices $[4,5]$. Unlike other FACTS devices, the UPFC can control active and reactive power, or adjust system parameters through injecting a series voltage with the desired amplitude and phase angle into the transmission line. The theoretical transmission capacity potential can be realized, thus increasing the practical capacity of existing systems with an essential stability level. The system stability can be enhanced by injecting or compensating required active and reactive power. The UPFC was designed to solve problems facing the power delivery industry, such as real-time control, dynamic compensation, and multifunctional flexibility [6]. Current active research on the UPFC mainly addresses new controller design [1], optimal location and size determination [7, 8], impacts on system devices [9], and new topology development such as transformerless UPFCs [10, 11], and matrix converter based unified power flow controllers (MC-UPFCs) [12-14]. The back-to-back converter is the core of the UPFC and its linear operating regions have been evaluated recently in [15]. The MC-UPFC is a promising technology and more efforts need to be dedicated to its development.

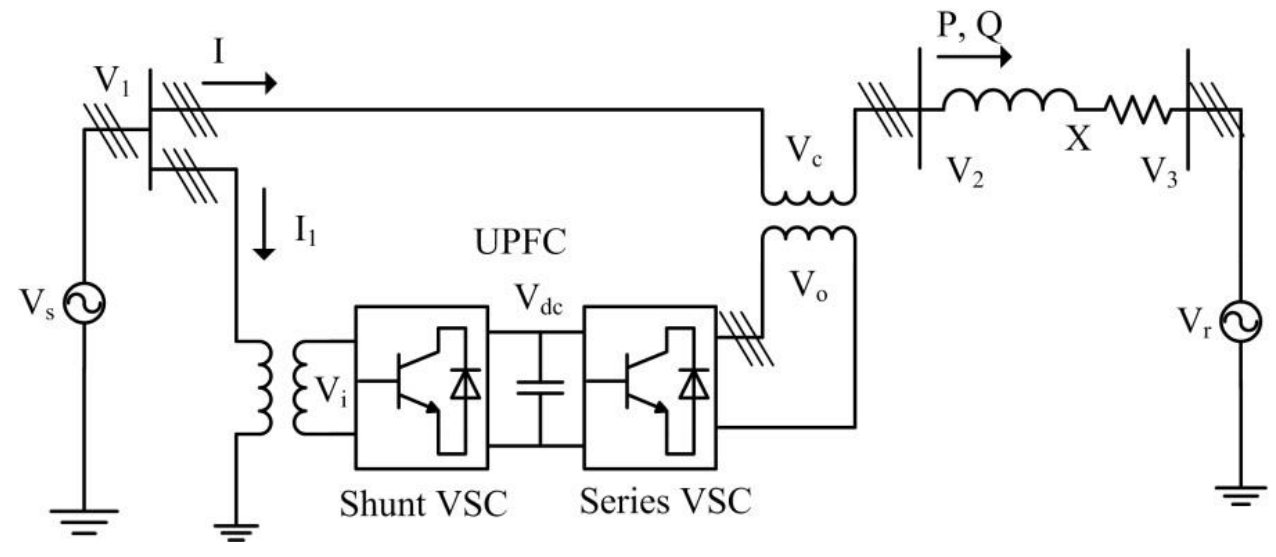

Fig. 1. Conventional UPFC system in a transmission line

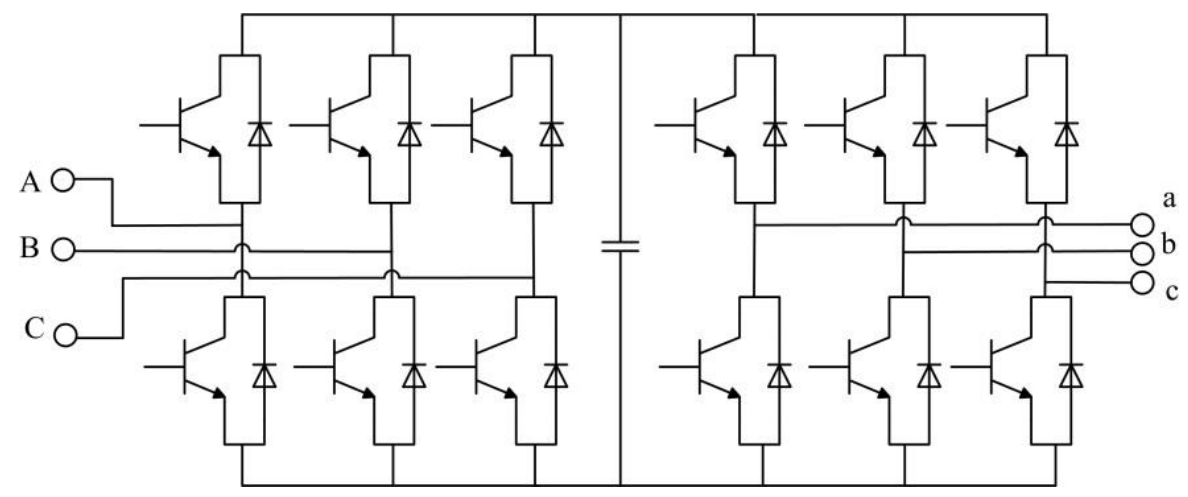

Fig. 2. Back-to-back converter topology in the UPFC 
The traditional UPFC system in a transmission line is shown in Fig. 1. It employs a back-to-back converter (as shown in Fig. 2.) which can fulfill indirect AC-to-AC conversion (AC/DC/AC). This structure usually consists of two voltage source converters (VSCs): a shunt VSC, which acts as a static synchronous compensator (STATCOM); and a series VSC, which acts as a static synchronous series compensator (SSSC). They are back-to-back connected with a capacitor across the DC link for energy storage. The STATCOM is connected in parallel with the transmission line by a transformer and it can work as a controllable current source, thus giving dynamic compensation of the reactive power. The SSSC is connected in series with the system and it is able to generate a series voltage with controlled amplitude and phase angle in order to adjust the system parameters, thereby facilitating the active power exchange between the transmission lines and the control of reactive power. Therefore, the power transfer capacity of the transmission line can be controlled in a flexible manner. However, the bulky capacitor in the conventional UPFC introduces extra losses, increases the weight and volume, requires DC voltage control and deteriorates with time [16]. Efforts have been devoted to the removal of the DC-link capacitor in [17]. However, the DC link still exists in the structure resulting in the requirement for DC voltage control.

Bulky energy storage elements are not required in the matrix converter, as illustrated in Fig. 3. This arrangement has attracted abundant research because of its compact configuration, bidirectional power-flow capability, high efficiency, controllable input power factor, and longer life cycle [18]. The matrix converter gives direct AC-to-AC conversion and it can be regarded as a competitive alternative to the back-to-back converter in various applications [19]. In fact, the matrix converter and its derivatives have found tremendous applications [20-22], and they are especially attractive for applications where system volume is a significant issue, e.g., in aerospace applications [23]. There are examples of the industrial application of the matrix converter. Several manufacturers, such as Yaskawa [24], Eupec [18][25] and Fuji [26] have produced commercial matrix converter modules and products. For the Yaskawa MX1S series of matrix converters, the nominal power capacity can reach 6 MVA. Hence, the matrix converter is a promising candidate for the industrial applications such as motor drives, interfacing different systems, microgrid and power flow control. 


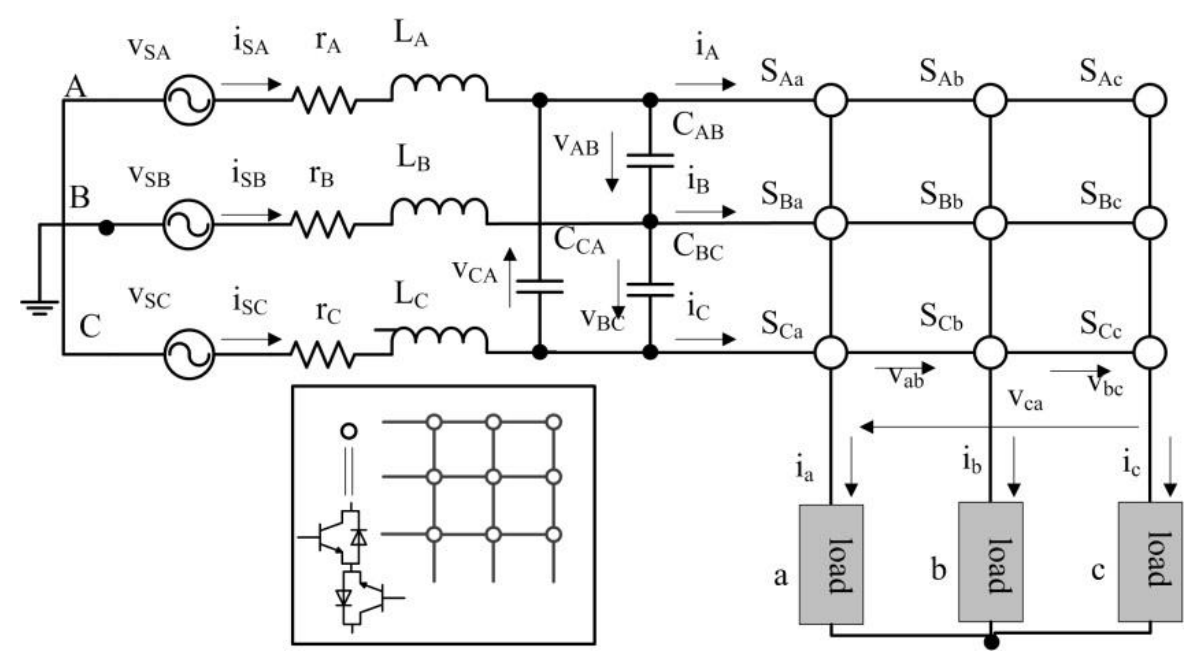

Fig. 3. The matrix converter system with the input filters and loads

Since the concept of the MC-UPFC was reported in [27], further work has developed the understanding of the controller. Although existing literature is limited, they have adequately demonstrated the competence of the matrix converter working as a power flow controller [28]. A two-stage control design is needed in this application; the first stage is the modulation of the matrix converter and the second stage is power flow control. These stages are closely related to the system controllable regions. In terms of the first stage, Space Vector Modulation (SVM) [29] is renowned for making the best use of the input voltage while reducing the number of commutations, controlling the input power factor independently and providing better power quality; therefore, this paper adopts direct SVM for the matrix converter modulation. Regarding the MC-UPFC, one significant contribution is from [16], in which a direct power controller was designed and good results were obtained. Whereas the controller is complex due to the nonlinear sliding mode controller involved in the control scheme. The complex vector synchronous frame PI current regulator was proposed in [30] in order to improve the transient response, which is limited in traditional PI current controllers due to its dependence on system synchronous frequency. Obtained results showed that the overshoot is restrained and the transient response is slightly improved, nevertheless there is increased complexity because six PI controllers have to be employed in the controller design. None of these studies has investigated the power controllable regions for the MC-UPFC. In this paper, controllable regions are analyzed for the MC-UPFC, and then a simple decoupling controller scheme involving only two PID controllers is designed for controlling active and reactive power flow with the MC-UPFC. 
The main contributions of this work include: (1) the full controllable regions of the transmission system without and with MC-UPFC are analyzed and the source contributions to the power controllability are investigated; (2) effective and simple PID controllers are developed involving the SVM for controlling the power flow in transmission systems; (3) the direct SVM and decoupling control for a MC-UPFC are detailed and decoupling effects are suppressed and (4) this paper presents a pattern of the closed-loop controller design for the MC-UPFC. The paper is organized as follows. In Section 2, the power-flow control theory and complete power-flow controllable regions are detailed. The direct SVM for the matrix converter is described in Section 3. Section 4 illustrates the PID controller design. Simulation results are presented in Section 5 followed by the conclusions.

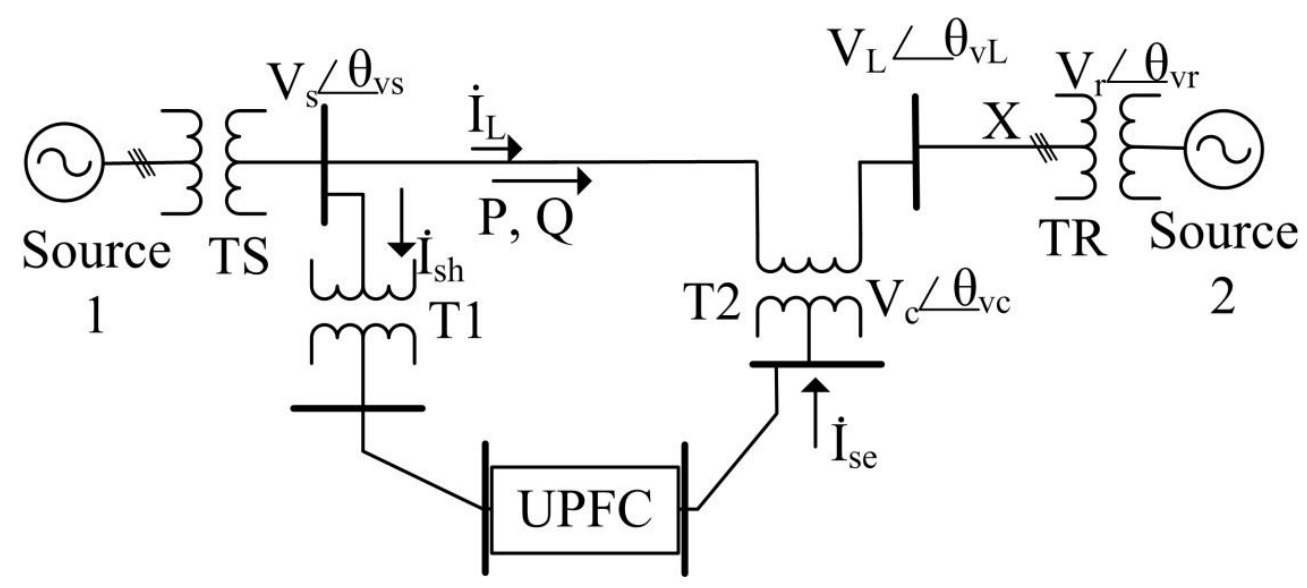

Fig. 4. Diagram for UPFC power-flow control

\section{Power Flow Control Theory and Controllable Regions Analysis}

\subsection{Power Flow Control Theory}

The UPFC when deployed in a transmission system is shown in Fig. 4 and the complex power $\dot{S}$ through the transmission line $X$ can be expressed as,

$$
\dot{S}=P+j Q=\dot{V}_{L}\left(\frac{\dot{V}_{L}-\dot{V}_{r}}{X}\right)^{*}
$$

where $X=R_{L}+j \omega L_{L}\left(\omega=2 \pi f\right.$ is the angular frequency, $R_{L}$ and $L_{L}$ the resistance and reactance respectively) is the transmission line impedance. The resistance can be neglected for high voltage applications, because the ratio of $\omega L_{L}$ to $R_{L}$ is sufficiently large [31]. Here $\left(\dot{V}^{*}\right.$ denotes the conjugate of $\dot{V}$, and phasors $\dot{V}_{L}=\dot{V}_{s}+\dot{V}_{c}$ and $\dot{V}_{r}$ are shown in the Fig. 4. 
From Fig. 4, if the compensation voltage from the UPFC is zero, i.e., $\dot{V}_{c}=0$, as a result, $\dot{V}_{s}=\dot{V}_{L}$, and (1) becomes

$$
P_{0}+j Q_{0}=\dot{V}_{s}\left(\frac{\dot{V}_{s}-\dot{V}_{r}}{j \omega L}\right)^{*}=\frac{V_{s} V_{r} \sin \theta}{\omega L}+j \frac{V_{s}\left(V_{s}-V_{r} \cos \theta\right)}{\omega L}
$$

where $\theta=\theta_{v s}-\theta_{v r}$ is the transmission angle of the system, being the phase difference between the sending and receiving end voltages. According to (2), with an assumption that amplitude $\mathrm{V}_{r} \leq \mathrm{V}_{s}$, the system power operating regions can be obtained for different amplitudes $\left(0 \sim \mathrm{V}_{\mathrm{s}}\right)$ and phase angles $\left(0 \sim 360^{\circ}\right)$ of the receiving end voltage. They are shown in Figs. 5 and 6, from which we can see that the mesh cross sections with $V_{r}=V_{s}$ will result in typical system power curves as displayed on the left-hand sides of the figures.
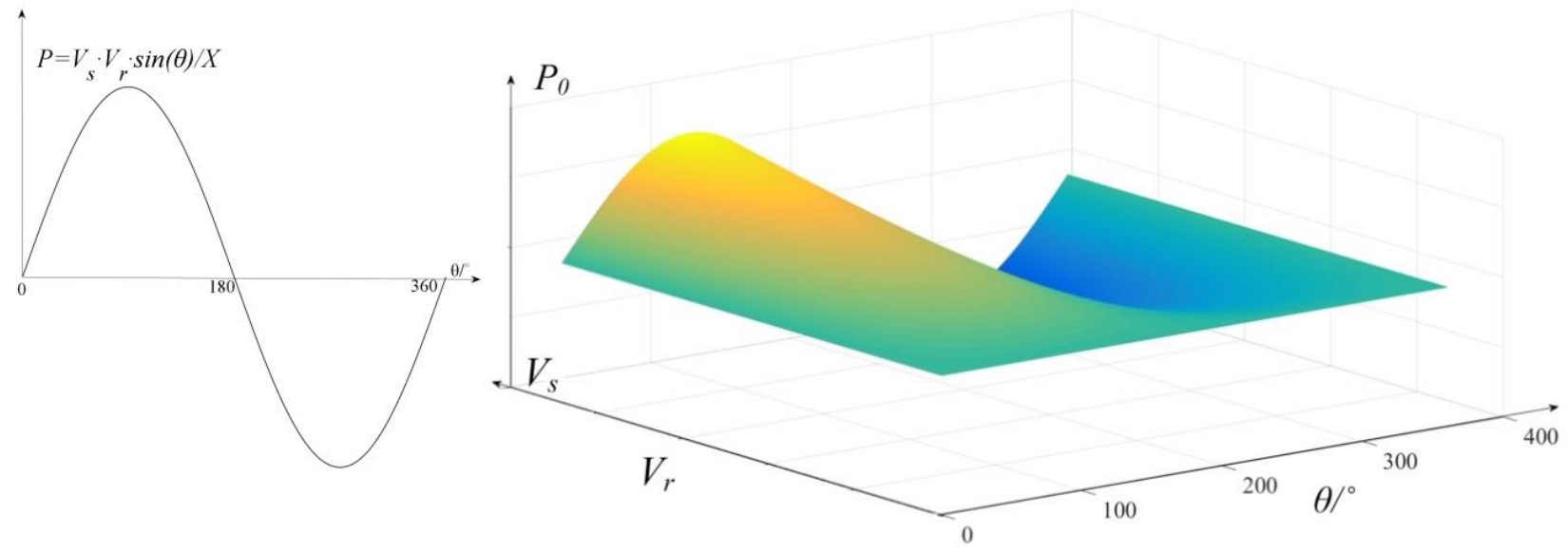

Fig. 5. Transmission system inherent active power curves versus $V_{r}$ and $\theta$
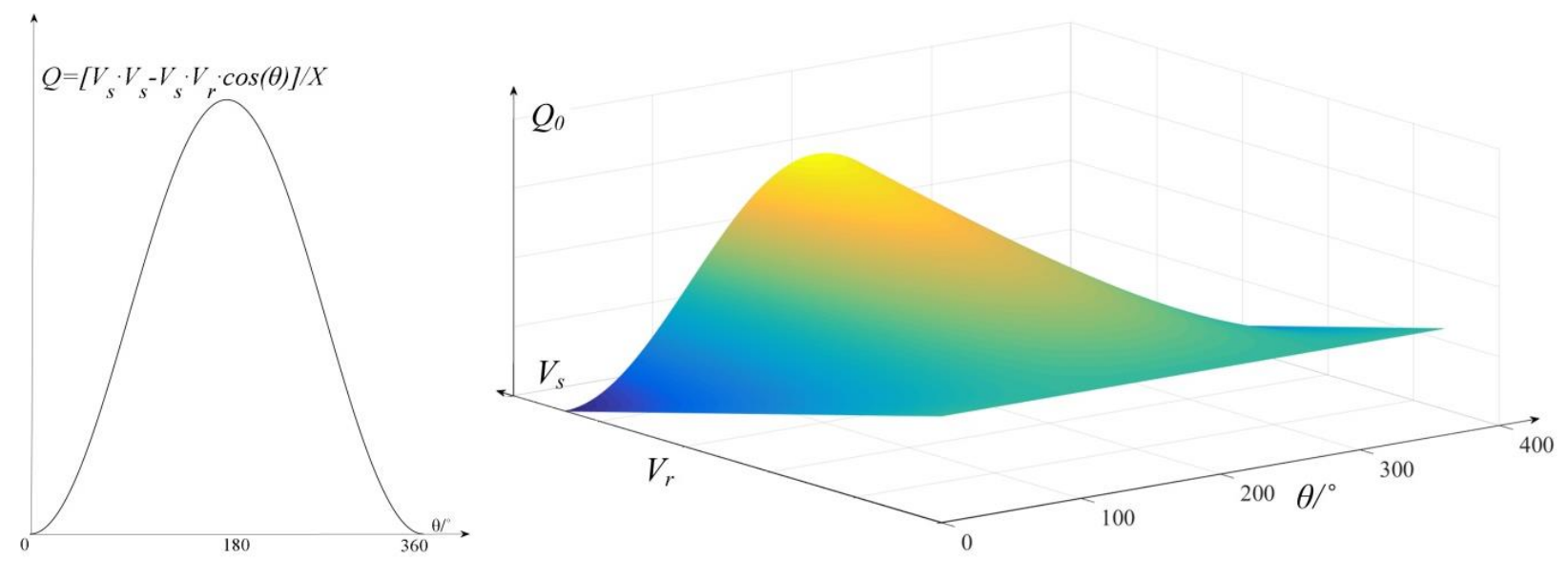

Fig. 6. Transmission system inherent reactive power curves versus $V_{r}$ and $\theta$

Similarly, when the injected voltage $\dot{\mathrm{V}}_{c} \neq 0$, the transmission line active and reactive power before the compensation point are obtained from (3). 


$$
\begin{aligned}
P+j Q & =\dot{V}_{s} \dot{I}_{L}^{*}=\dot{V}_{s}\left(\frac{\dot{V}_{s}+\dot{V}_{c}-\dot{V}_{r}}{j \omega L}\right)^{*} \\
& =\frac{1}{\omega L}\left\{\left[V_{s} V_{r} \sin \theta+j\left(V_{s}^{2}-V_{s} V_{r} \cos \theta\right)\right]+\left[V_{c} V_{s} \sin \left(\theta_{v c}-\theta_{v s}\right)+j V_{c} V_{s} \cos \left(\theta_{v c}-\theta_{v s}\right)\right]\right\} \\
& =\left(P_{0}+j Q_{0}\right)+\left(\Delta P_{1}+j \Delta Q_{1}\right)
\end{aligned}
$$

According to (3) the active and reactive power through the lines are divided into the uncontrollable part (2) and the controllable part $\left(\Delta P_{1}\right.$ and $\left.\Delta Q_{1}\right)$. By controlling the amplitude and phase angle of $\dot{V}_{\mathrm{c}}$, the active and reactive power through the transmission line can be regulated. In steady state, the MC-UPFC does not consume any real power, except the losses. DC-link losses do not exist in the MC-UPFC.

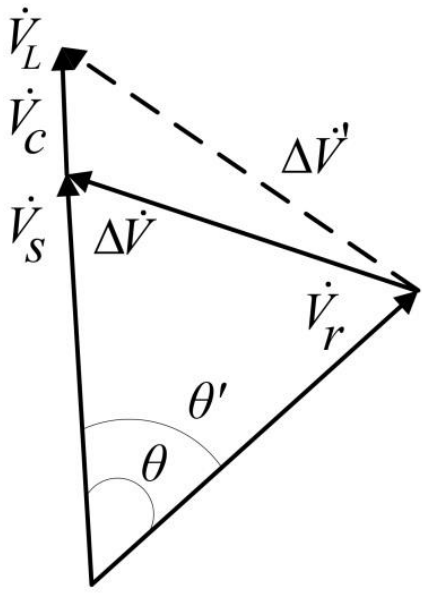

(a)

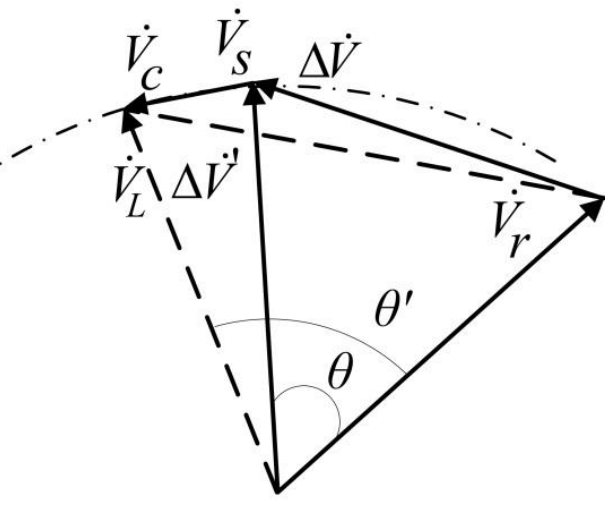

(b)

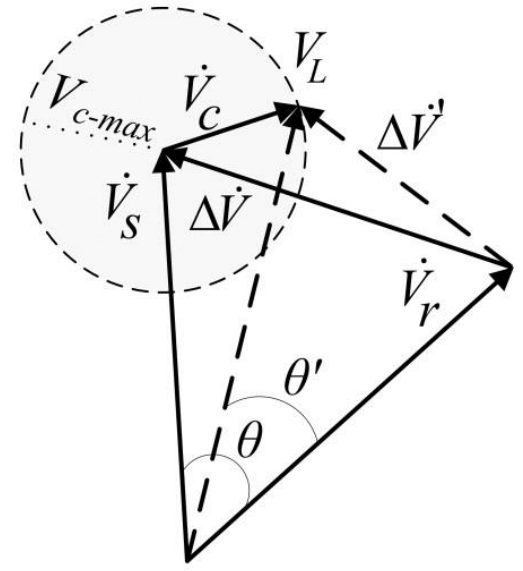

(c)

Fig. 7. Phasor diagrams of the transmission line with UPFC under modes of (a) Sending end voltage compensation,

(b) Transmission angle compensation and (c) Comprehensive compensation

The system phasor diagrams are shown in Fig. 7. The UPFC can operate in voltage, transmission angle, impedance and comprehensive compensation modes. The compensated voltage $V_{c}$ can have a maximum voltage $V_{c-\max }$ which is only determined by the UPFC rated capacity while phase angles have a range of $360^{\circ}$ as shown by the shaded circle in Fig. 7 (c). With a given UPFC capacity, the controllable active power $\Delta P_{l}$ and reactive power $\Delta Q_{1}$ can be obtained as a function of the compensated voltage amplitudes $V_{c}$ and phase angles $\theta_{c}$, as shown in Figs. 8 and 9. These controllable regions are only limited by the designed UPFC capacity. Combining the system inherent active and reactive power (Figs. 5 and 6) with these controllable power (Figs. 8 and 9), we can get the total sending-end transmitting power which are enhanced in a flexible manner by the UPFC. 


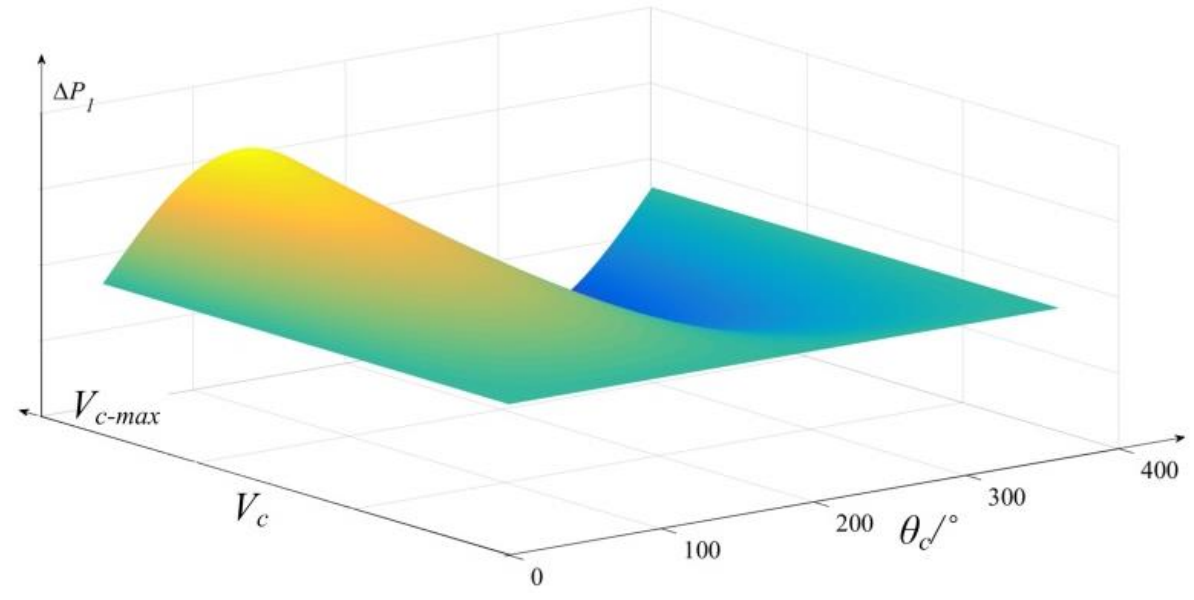

Fig. 8. Controllable active power diagram as a function of UPFC's $V_{c}$ and $\theta_{c}$

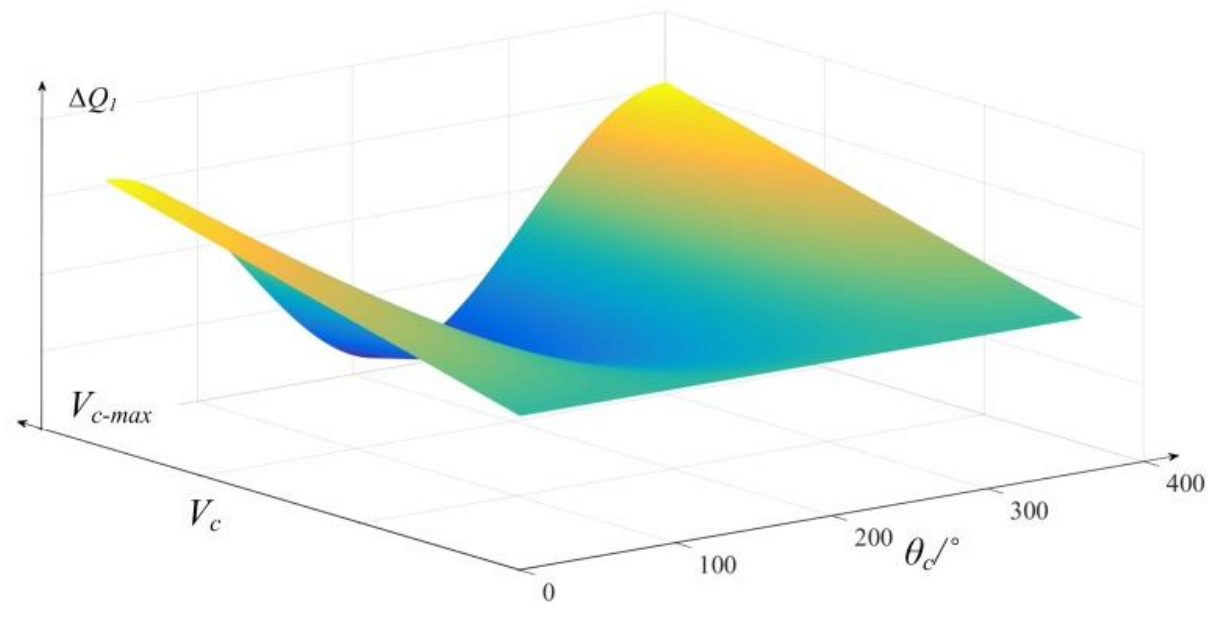

Fig. 9. Controllable reactive power diagram as a function of UPFC's $V_{c}$ and $\theta_{c}$

It is assumed that the receiving-end voltage amplitude range is $0 \leq V_{r} \leq V_{s}$, and the transmission angle range is $0 \leq \theta \leq 360^{\circ}$. With a UPFC of the fixed capacity, the full achievable power regions for the sending end of the system can be derived, as shown in Fig. 10. In this figure, if $V_{r}$ is fixed while $\theta$ is varying, then the angle passages are obtained and they are denoted by two adjacent parallel lines. They are only drawn for angles of $60^{\circ} / 240^{\circ}, 90^{\circ} / 270^{\circ}$ and $150^{\circ} / 330^{\circ}$ for the purpose of clear visibility. If $\theta$ is fixed while $V_{r}$ is varying, then the loci denoted by the cyan circles are obtained. Only two loci are sketched here, i.e. $V_{r}=V_{s}$ and $V_{r}=$ $0.5 V_{s}$

In the Fig. 10, the small bold circles represent the UPFC rated controllable region at different values of $V_{r}$ and $\theta$. Each circle corresponds specifically to the system original operating point, being the center point of that circle. For example, the small blue circle shown in the figure has the center point located on the $V_{r}=0.5 V_{s}$ locus and it lies in the $\theta=150^{\circ}$ passage, these indicate the blue circle is the UPFC controllable 
region for the operating point of $\left(V_{r}=0.5 V_{s}, \theta=150^{\circ}\right)$. Only a limited number of operating points and their corresponding UPFC controllable regions are shown here. The outermost red dashed circle is the fully achievable power region of the transmission system with the UPFC compensation. Again, from this figure, it is evident that the system power controllability has become more flexible and power transfer capacity can be improved.

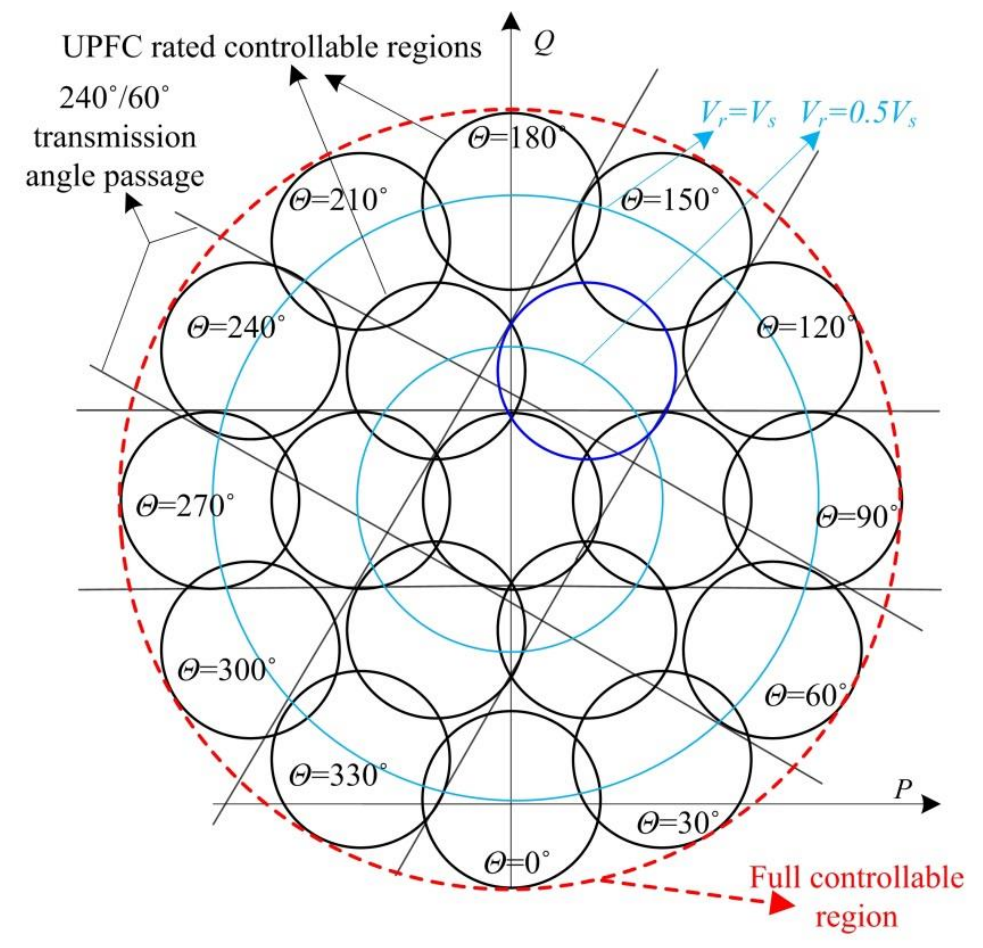

Fig. 10. Full power controllable regions with the application of UPFC

In addition to the contribution of the power controllability from the point before compensation (which is a result of current compensation), the UPFC can directly compensate the active and reactive power. This is obtained from the voltage compensation. Therefore, there are two sources of contribution for the power controllability in the transmission line $X$, as compensated by a UPFC. The total complex power flowing through the transmission line $X$ after the compensation point is

$$
\begin{aligned}
& P+j Q=\dot{V}_{L} \dot{I}_{L}^{*}=\left(\dot{V}_{s}+\dot{V}_{c}\right)\left(\frac{\dot{V}_{s}+\dot{V}_{c}-\dot{V}_{r}}{j \omega L}\right)^{*}
\end{aligned}
$$

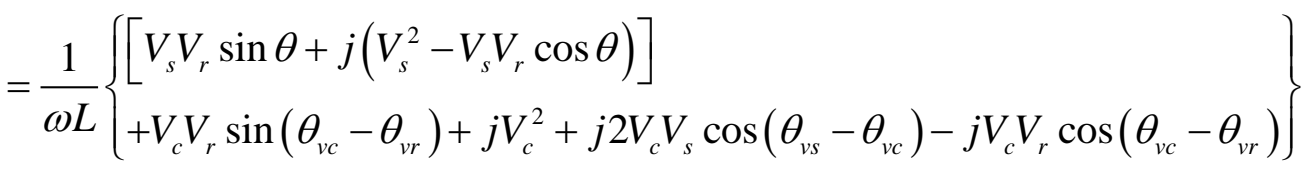

$$
\begin{aligned}
& =\left(P_{0}+j Q_{0}\right)+\left(\Delta P_{2}+j \Delta Q_{2}\right)
\end{aligned}
$$


and the power provided by the UPFC's injected voltage (voltage contribution) becomes:

$$
\begin{aligned}
\Delta S & =\Delta P+j \Delta Q=\Delta P_{2}-\Delta P_{1}+j\left(\Delta Q_{2}-\Delta Q_{1}\right) \\
& =\frac{1}{\omega L}\left[\begin{array}{l}
V_{c} V_{s} \sin \left(\theta_{v s}-\theta_{v c}\right)+V_{c} V_{r} \sin \left(\theta_{v c}-\theta_{v r}\right) \\
+j V_{c}^{2}+j V_{c} V_{s} \cos \left(\theta_{v c}-\theta_{v s}\right)-j V_{c} V_{r} \cos \left(\theta_{v c}-\theta_{v r}\right)
\end{array}\right]
\end{aligned}
$$

Hence, the mesh curves for $\Delta P$ and $\Delta Q$, as transferred by the power flow controller due to the voltage compensation, can be derived. This is studied in the simulation study case in the simulation section (Figs. 15 and 16).

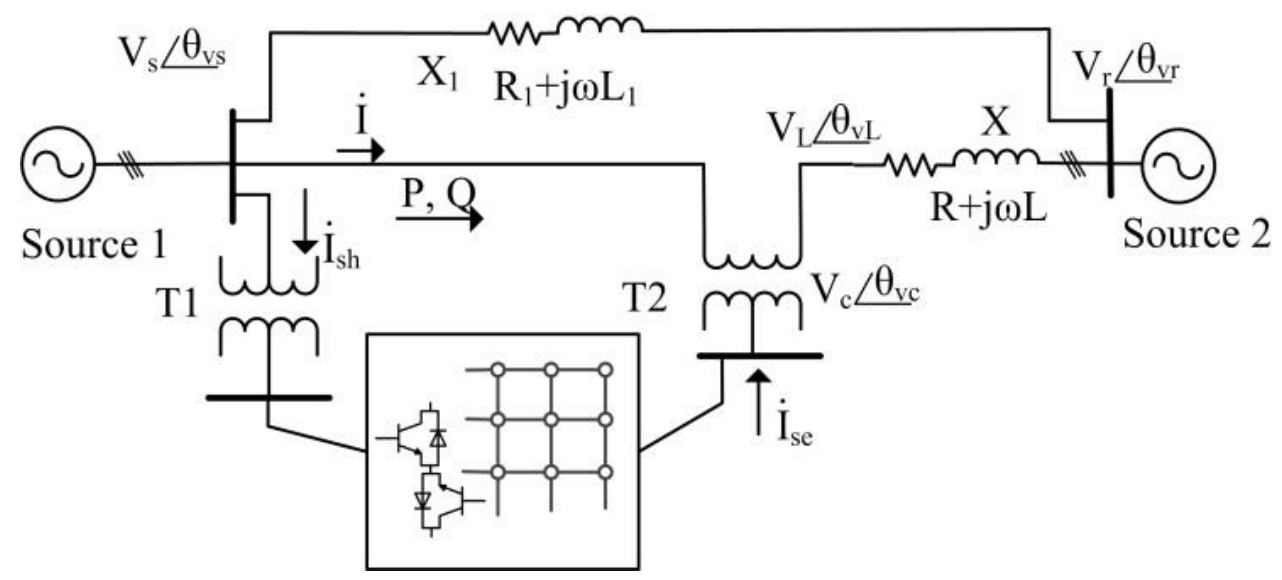

Fig. 11. MC-UPFC in double-lie transmission system (simulation study case)

\subsection{MC-UPFC System in the Transmission Line}

A UPFC based on a direct SVM controlled matrix converter is shown in Fig. 11 for one branch in a double-line transmission system. Transformers T1 and T2 are employed to connect the input and output terminals of the MC-UPFC to the transmission line. The input and output sides are connected in shunt and series with the transmission line respectively. Direct SVM will be elaborated on in the next section. The MC-UPFC is proposed for power compensation through one of the lines in a double-line system. The simulation studies are based on this system.

\section{Matrix Converter Direct SVM Modulation}

SVM is a PWM technique for synthesizing the instantaneous space vector representation of the desired output voltages and input currents by selecting the appropriate available input voltage and output current vectors. For a matrix converter, it includes indirect and direct SVM both of which have similar performance [14]. As direct SVM provides a better understanding of the principles of a matrix converter, it is employed 
in this work to generate the desired output voltages from the matrix converter to meet the requirements of power flow control. In the matrix converter topology, the allowed number of switch-state combinations is 27 in total excluding states that cause short circuits on the source sides or cause open circuits on the load sides. Consider a balanced three-phase input phase voltage set applied to a matrix converter:

$$
\begin{aligned}
& V_{A}=V_{i} \sin \left(\omega_{i} t\right) \\
& V_{B}=V_{i} \sin \left(\omega_{i} t-2 \pi / 3\right) \\
& V_{C}=V_{i} \sin \left(\omega_{i} t+2 \pi / 3\right)
\end{aligned}
$$

where $V_{i}$ is the amplitude of input phase voltages and $\omega_{i}=2 \pi f_{i}$ is the input angular frequency. The matrix converter output current can be presented by:

$$
\begin{aligned}
& I_{a}=I_{o} \sin \left(\omega_{o} t-\varphi_{o}\right) \\
& I_{b}=I_{o} \sin \left(\omega_{o} t-\varphi_{o}-2 \pi / 3\right) \\
& I_{c}=I_{o} \sin \left(\omega_{o} t-\varphi_{o}+2 \pi / 3\right)
\end{aligned}
$$

where $I_{o}$ is the amplitude of output currents, $\omega_{o}=2 \pi f_{o}$ the output angular frequency and $\varphi_{o}$ the angle difference between the output voltage and output current. The three-phase system can be expressed by space vectors by using the transformation:

$$
x_{S}=\frac{2}{3}\left(x_{1}+\alpha x_{2}+\alpha^{2} x_{3}\right)
$$

where $x_{1,2,3}$ are the variables in the three-phase system; $\alpha=e^{j(2 \pi / 3)}$ and $\alpha^{2}=e^{j(4 \pi / 3)}$ and $x_{s}$ is the corresponding space vector after the transformation. The desired output voltages (9) and input currents (10) are also transformed using (8) to determine the location of the desired vectors at any instant.

$$
\begin{aligned}
& V_{a}=V_{o} \sin \left(\omega_{o} t+\varphi\right) \\
& V_{b}=V_{o} \sin \left(\omega_{o} t+\varphi-2 \pi / 3\right) \\
& V_{c}=V_{o} \sin \left(\omega_{o} t+\varphi+2 \pi / 3\right) \\
& I_{A}=I_{i} \sin \left(\omega_{i} t-\varphi_{i}\right) \\
& I_{B}=I_{i} \sin \left(\omega_{i} t-\varphi_{i}-2 \pi / 3\right) \\
& I_{C}=I_{i} \sin \left(\omega_{i} t-\varphi_{i}+2 \pi / 3\right)
\end{aligned}
$$

where $V_{o}$ and $I_{i}$ are the amplitudes of expected output voltages and input currents, and $\varphi_{i}$ the input power factor angle and $\varphi$ the expected output voltage phase angle.

Table 1 Active states of matrix converter switch states 


\begin{tabular}{|c|c|c|c|c|}
\hline No. & Switches states & Output voltage vectors & Input current vectors & Group \\
\hline+1 & In & $V_{+1}=\frac{2}{\sqrt{3}} V_{i} \sin \left(\omega_{i} t+\frac{\pi}{6}\right) e^{j \cdot 0}$ & $I_{+1}=\frac{2}{\sqrt{3}} I_{o} \sin \left(\omega_{o} t-\varphi_{o}\right) e^{j-\frac{\pi}{6}}$ & \\
\hline+2 & $\mathrm{BH}$ & $V_{+2}=\frac{2}{\sqrt{3}} V_{i} \sin \left(\omega_{i} t-\frac{\pi}{2}\right) e^{j \cdot 0}$ & $I_{+2}=\frac{2}{\sqrt{3}} I_{o} \sin \left(\omega_{o} t-\varphi_{o}\right) e^{j \cdot \frac{\pi}{2}}$ & \\
\hline+3 & 38 & $V_{+3}=\frac{2}{\sqrt{3}} V_{i} \sin \left(\omega_{i} t+\frac{5 \pi}{6}\right) e^{j \cdot 0}$ & $I_{+3}=\frac{2}{\sqrt{3}} I_{o} \sin \left(\omega_{o} t-\varphi_{o}\right) e^{j \cdot \frac{7 \pi}{6}}$ & \\
\hline-1 & $\mathrm{HB}$ & $V_{-1}=-\frac{2}{\sqrt{3}} V_{i} \sin \left(\omega_{i} t+\frac{\pi}{6}\right) e^{j \cdot 0}$ & $I_{-1}=-\frac{2}{\sqrt{3}} I_{o} \sin \left(\omega_{o} t-\varphi_{o}\right) e^{j \cdot-\frac{\pi}{6}}$ & \\
\hline-2 & in & $V_{-2}=-\frac{2}{\sqrt{3}} V_{i} \sin \left(\omega_{i} t-\frac{\pi}{2}\right) e$ & $I_{-2}=-\frac{2}{\sqrt{3}} I_{o} \sin \left(\omega_{o} t-\varphi_{o}\right) e^{j \cdot \frac{\pi}{2}}$ & \\
\hline-3 & $\mathrm{Fon}$ & $V_{-3}=-\frac{2}{\sqrt{3}} V_{i} \sin \left(\omega_{i} t+\frac{5 \pi}{6}\right) \epsilon$ & $I_{-3}=-\frac{2}{\sqrt{3}} I_{o} \sin \left(\omega_{o} t-\varphi_{o}\right) e^{j \cdot \frac{7 \pi}{6}}$ & \\
\hline+4 & Bin & $V_{+4}=\frac{2}{\sqrt{3}} V_{i} \sin \left(\omega_{i} t+\frac{\pi}{6}\right) e^{j \cdot \frac{2 \pi}{3}}$ & $I_{+4}=\frac{2}{\sqrt{3}} I_{o} \sin \left(\omega_{o} t-\varphi_{o}-\frac{2 \pi}{3}\right) e^{j-\frac{\pi}{6}}$ & \\
\hline+5 & Pn & $V_{+5}=\frac{2}{\sqrt{3}} V_{i} \sin \left(\omega_{i} t-\frac{\pi}{2}\right) e^{j \cdot \frac{2 \pi}{3}}$ & $I_{+5}=\frac{2}{\sqrt{3}} I_{o} \sin \left(\omega_{o} t-\varphi_{o}-\frac{2 \pi}{3}\right) e^{j \cdot \frac{\pi}{2}}$ & \\
\hline+6 & Bq & $V_{+6}=\frac{2}{\sqrt{3}} V_{i} \sin \left(\omega_{i} t+\frac{5 \pi}{6}\right) e^{j \cdot \frac{2 \pi}{3}}$ & $I_{+6}=\frac{2}{\sqrt{3}} I_{o} \sin \left(\omega_{o} t-\varphi_{o}-\frac{2 \pi}{3}\right) e^{j \cdot \frac{7 \pi}{6}}$ & active \\
\hline-4 & 渵 & $V_{-4}=-\frac{2}{\sqrt{3}} V_{i} \sin \left(\omega_{i} t+\frac{\pi}{6}\right) e^{j \cdot \frac{2 \pi}{3}}$ & $I_{-4}=-\frac{2}{\sqrt{3}} I_{o} \sin \left(\omega_{o} t-\varphi_{o}-\frac{2 \pi}{3}\right) e^{j-\frac{\pi}{6}}$ & states \\
\hline-5 & 7 & $V_{-5}=-\frac{2}{\sqrt{3}} V_{i} \sin \left(\omega_{i} t-\frac{\pi}{2}\right) e^{j \cdot \frac{2 \pi}{3}}$ & $I_{-5}=-\frac{2}{\sqrt{3}} I_{o} \sin \left(\omega_{o} t-\varphi_{o}-\frac{2 \pi}{3}\right) e^{j \cdot \frac{\pi}{2}}$ & \\
\hline-6 & 78 & $V_{-6}=-\frac{2}{\sqrt{3}} V_{i} \sin \left(\omega_{i} t+\frac{5 \pi}{6}\right) e^{j \cdot \frac{2 \pi}{3}}$ & $I_{-6}=-\frac{2}{\sqrt{3}} I_{o} \sin \left(\omega_{o} t-\varphi_{o}+\frac{\pi}{3}\right) e^{j \cdot \frac{7 \pi}{6}}$ & \\
\hline+7 & 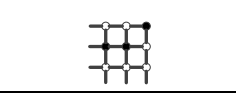 & $V_{+7}=\frac{2}{\sqrt{3}} V_{i} \sin \left(\omega_{i} t+\frac{\pi}{6}\right) e^{j \cdot \frac{4 \pi}{3}}$ & $I_{+7}=\frac{2}{\sqrt{3}} I_{o} \sin \left(\omega_{o} t-\varphi_{o}+\frac{2 \pi}{3}\right) e^{j-\frac{\pi}{6}}$ & \\
\hline+8 & 3 & $V_{+8}=\frac{2}{\sqrt{3}} V_{i} \sin \left(\omega_{i} t-\frac{\pi}{2}\right) e^{j \cdot \frac{4 \pi}{3}}$ & $I_{+8}=\frac{2}{\sqrt{3}} I_{o} \sin \left(\omega_{o} t-\varphi_{o}+\frac{2 \pi}{3}\right) e^{j \cdot \frac{\pi}{2}}$ & \\
\hline+9 & 3 & $V_{+9}=\frac{2}{\sqrt{3}} V_{i} \sin \left(\omega_{i} t+\frac{5 \pi}{6}\right) e^{j \cdot \frac{4 \pi}{3}}$ & $I_{+9}=\frac{2}{\sqrt{3}} I_{o} \sin \left(\omega_{o} t-\varphi_{o}+\frac{2 \pi}{3}\right) e^{j \cdot \frac{7 \pi}{6}}$ & \\
\hline-7 & Z18 & $V_{-7}=-\frac{2}{\sqrt{3}} V_{i} \sin \left(\omega_{i} t+\frac{\pi}{6}\right) e^{j \cdot \frac{4 \pi}{3}}$ & $I_{-7}=-\frac{2}{\sqrt{3}} I_{o} \sin \left(\omega_{o} t-\varphi_{o}+\frac{2 \pi}{3}\right) e^{j-\frac{\pi}{6}}$ & \\
\hline-8 & Hin & $V_{-8}=-\frac{2}{\sqrt{3}} V_{i} \sin \left(\omega_{i} t-\frac{\pi}{2}\right) e^{j \cdot \frac{4 \pi}{3}}$ & $I_{-8}=-\frac{2}{\sqrt{3}} I_{o} \sin \left(\omega_{o} t-\varphi_{o}+\frac{2 \pi}{3}\right) e^{j 0 \frac{\pi}{2}}$ & \\
\hline-9 & $\pi$ & $V_{-9}=-\frac{2}{\sqrt{3}} V_{i} \sin \left(\omega_{i} t+\frac{5 \pi}{6}\right) e^{j \cdot \frac{4 \pi}{3}}$ & $I_{-9}=-\frac{2}{\sqrt{3}} I_{o} \sin \left(\omega_{o} t-\varphi_{o}+\frac{2 \pi}{3}\right) e^{j \cdot \frac{7 \pi}{6}}$ & \\
\hline
\end{tabular}

For the SVM, the available switch combinations in a matrix converter can be divided into the three groups i.e., active, zero and rotating states, as shown in Tables 1 and 2. In the Switches states column, a solid circle means the corresponding switches are turned on, for example, $\mathrm{S}_{\mathrm{Aa}}, \mathrm{S}_{\mathrm{Bb}}$ and $\mathrm{S}_{\mathrm{Bc}}$ are turned on in the case of switch No. +1 . Among the 27 available states, only 21 states (18 active and 3 zero states) are considered useful in SVM to synthesize the desired output voltage vectors and input current vectors [32], which limits the flexibility. In contrast, all 27 states can be involved in the model predictive control (MPC) 
[33], so the flexibility can be improved further using this simple control method. This remains an open topic.

These states are plotted in Fig. 12 and they form the hexagons.

Table 2 Zeros states and rotating states of matrix converter switch states

\begin{tabular}{|c|c|c|c|c|}
\hline No. & Switches states & Output voltage vector & Input voltage vector & Group \\
\hline 01 & 78 & $V_{01}=0$ & $I_{01}=0$ & \multirow{3}{*}{$\begin{array}{l}\text { zero } \\
\text { states }\end{array}$} \\
\hline 02 & 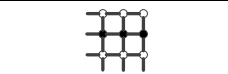 & $V_{02}=0$ & $I_{02}=0$ & \\
\hline 03 & 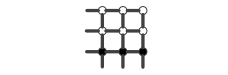 & $V_{03}=0$ & $I_{03}=0$ & \\
\hline $\mathrm{r} 1$ & $\mathrm{En}$ & $V_{r 1}=V_{i} e^{j \cdot \arctan \left(-\cot \left(\omega_{i} t\right)\right)}$ & $I_{r 1}=I_{o} e^{j \cdot \arctan \left(-\cot \left(\omega_{o} t-\varphi_{o}\right)\right)}$ & \multirow{6}{*}{$\begin{array}{c}\text { rotating } \\
\text { states }\end{array}$} \\
\hline $\mathrm{r} 2$ & int & $V_{r 2}=V_{i} e^{j \cdot \arctan \left(\cot \left(\omega_{i} t\right)\right)}$ & $I_{r 2}=I_{o} e^{j \cdot \arctan \left(\cot \left(\omega_{o} t-\varphi_{o}\right)\right)}$ & \\
\hline r3 & Pas & $V_{r 3}=-V_{i} e^{j \cdot \arctan \left(\cot \left(\omega_{i} t-\frac{\pi}{3}\right)\right)}$ & $I_{r 3}=-I_{o} e^{j \cdot \arctan \left(\cot \left(\omega_{o} t-\varphi_{o}-\frac{\pi}{3}\right)\right)}$ & \\
\hline $\mathrm{r} 4$ & 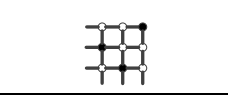 & $V_{r 4}=-V_{i} e^{j \cdot \arctan \left(-\cot \left(\omega_{i} t+\frac{\pi}{3}\right)\right)}$ & $I_{r 4}=-I_{o} e^{j \cdot \arctan \left(-\cot \left(\omega_{o} t-\varphi_{o}-\frac{\pi}{3}\right)\right)}$ & \\
\hline r5 & $\mathrm{Fin}$ & $V_{r 5}=-V_{i} e^{j \cdot \arctan \left(\cot \left(\omega_{i}+\frac{\pi}{3}\right)\right)}$ & $I_{r 5}=-I_{o} e^{j \cdot \arctan \left(\cot \left(\omega_{o} t-\varphi_{o}+\frac{\pi}{3}\right)\right)}$ & \\
\hline r6 & Zit & $V_{r 6}=-V_{i} e^{j \cdot \arctan \left(-\cot \left(\omega_{i} t-\frac{\pi}{3}\right)\right)}$ & $I_{r 6}=-I_{o} e^{j \cdot \arctan \left(-\cot \left(\omega_{o} t-\varphi_{o}+\frac{\pi}{3}\right)\right)}$ & \\
\hline
\end{tabular}
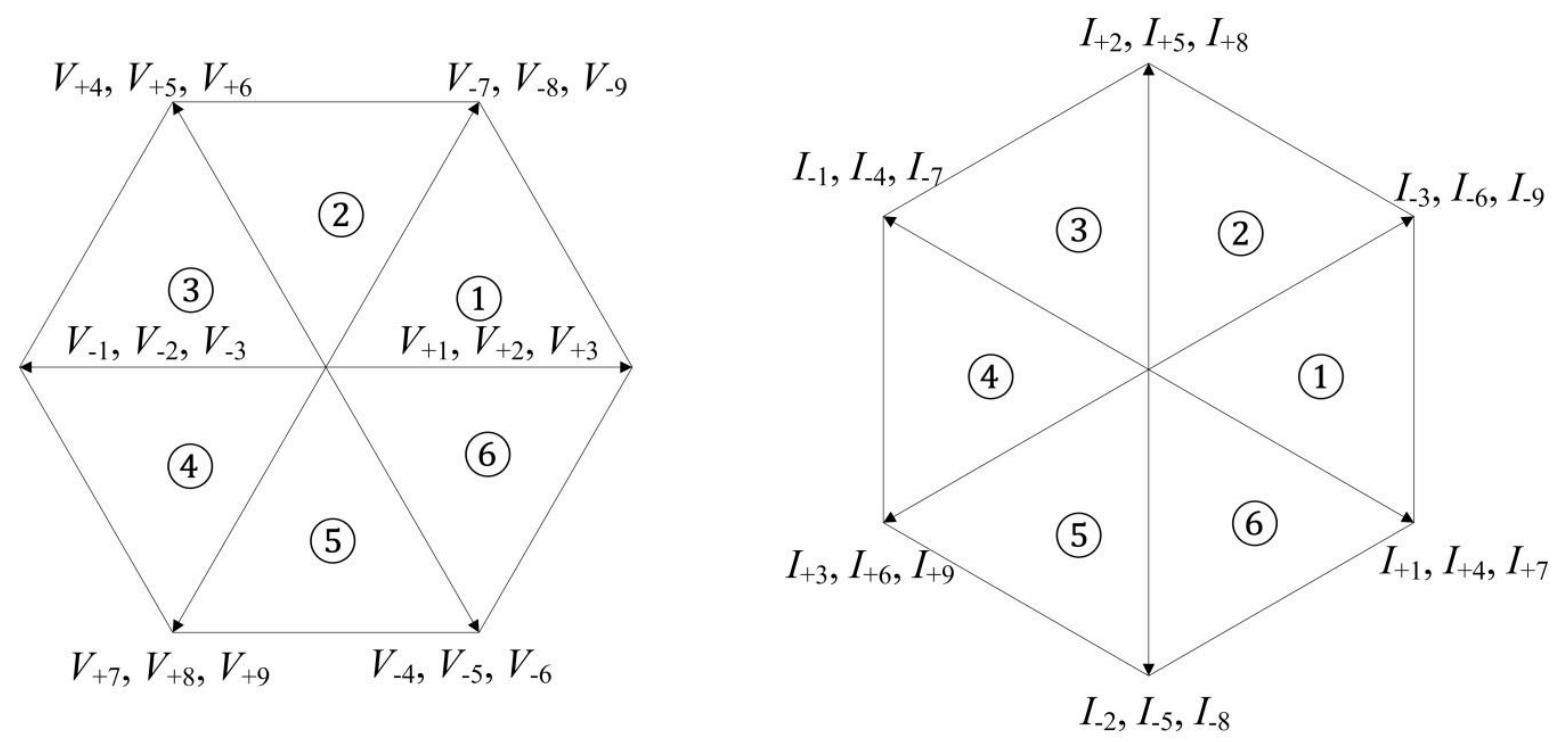

Fig. 12. Input voltage and output current vectors hexagons 

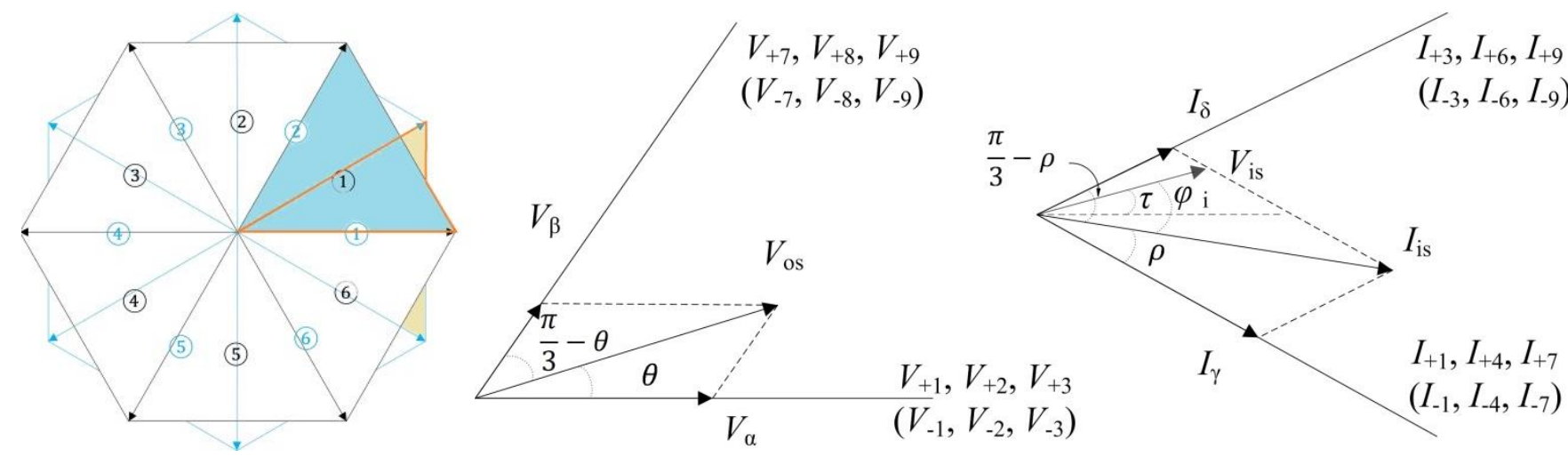

Fig. 13. Synthesis illustration of the output voltage and input current vectors

In the SVM scheme, the nearest adjacent vectors to the expected vector are utilized to synthesize the required vectors. The application of non-adjacent vectors may produce higher THD and/or switching losses [34]. The chosen vectors must accomplish the synthesis of both output voltages (9) and input currents (10) at the same time and they are summarized and tabulated in Table 3. In order to explain the algorithm, without loss of generality, it is assumed that, at a given time instant, both desired output voltage and input current vectors appear in sector (1) of each hexagon shown in Fig. 13. The expected output voltage and input current space vectors can be decomposed into $V_{\alpha}$ and $V_{\beta}, I_{\gamma}$ and $I_{\delta}$ respectively as shown in Fig. 13. Once the switch states are determined (Table 3) the corresponding working times for each switch are calculated. According to Figs. 12 and 13 and Table 3, the working times for applied vectors are formulated in (11) to (16).

$$
\begin{aligned}
t_{x 1} & =(-1)^{m+n} \frac{2}{\sqrt{3}} T_{P} q \frac{\sin (\theta) \sin (\rho)}{\cos \left(\varphi_{i}\right)} \\
t_{x 2} & =(-1)^{m+n+1} \frac{2}{\sqrt{3}} T_{P} q \frac{\sin (\theta) \sin (\pi / 3-\rho)}{\cos \left(\varphi_{i}\right)} \\
t_{y 1} & =(-1)^{m+n+1} \frac{2}{\sqrt{3}} T_{P} q \frac{\sin (\pi / 3-\theta) \sin (\rho)}{\cos \left(\varphi_{i}\right)} \\
t_{y 2} & =(-1)^{m+n} \frac{2}{\sqrt{3}} T_{P} q \frac{\sin (\pi / 3-\theta) \sin (\pi / 3-\rho)}{\cos \left(\varphi_{i}\right)} \\
t_{0} & =T_{P}-\left(\left|t_{x 1}\right|+\left|t_{x 2}\right|+\left|t_{y 1}\right|+\left|t_{y 2}\right|\right) \\
q & =\frac{V_{o}}{V_{i}} \leq\left|\frac{\sqrt{3} \cos \left(\varphi_{i}\right)}{2 \sin (\theta+\pi / 3) \sin (\rho+\pi / 3)}\right|
\end{aligned}
$$


In these formulae, $0 \leq \theta \leq \pi / 3$ is the anglular difference between the desired output space vector $V_{o s}$ and its corresponding right-hand adjacent vector $V_{\alpha .} 0 \leq \rho \leq \pi / 3$ is the angle between the desired input space vector $I_{i s}$ and its corresponding right-hand adjacent vector $I_{\gamma} . t_{x 1}, t_{x 2}$ and $t_{y 1}, t_{y 2}$ are working times for the selected vectors and $T_{p}$ is the cycle period. $m$ and $n$ denote $(m, n=1,2,3,4,5,6)$ the $m^{\text {th }}$ output voltage vector sector and the $n^{\text {th }}$ input current vector sector. If any of the working times is negative, then the corresponding negative vector should be selected instead of the assumed positive vector as shown in Table 3. Note that correct commutation techniques and switching sequences are necessary to improve waveforms quality and avoid contingencies caused by unexpected short or open circuits. However, they are not discussed in this work.

Table 3 Vectors selection to synthesize the expected voltage and current vectors

\begin{tabular}{|c|c|c|c|c|c|c|c|c|c|c|c|c|c|}
\hline \multicolumn{14}{|c|}{ Sector number of the output voltage vector } \\
\hline \multirow{7}{*}{$\begin{array}{l}\text { Sector } \\
\text { number } \\
\text { of } \\
\text { input } \\
\text { current } \\
\text { vector }\end{array}$} & \multicolumn{5}{|c|}{1,4} & \multicolumn{4}{|c|}{2,5} & \multicolumn{4}{|c|}{3,6} \\
\hline & 1 & \multicolumn{4}{|c|}{$+7,+9,+1,+3$} & \multicolumn{4}{|c|}{$+4,+6,+7,+9$} & \multicolumn{4}{|c|}{$+1,+3,+4,+6$} \\
\hline & 2 & \multicolumn{4}{|c|}{$+8,+7,+2,+1$} & \multicolumn{4}{|c|}{$+5,+4,+8,+7$} & \multicolumn{4}{|c|}{$+2,+1,+5,+4$} \\
\hline & 3 & \multicolumn{4}{|c|}{$+9,+8,+3,+2$} & \multicolumn{4}{|c|}{$+6,+5,+9,+8$} & \multicolumn{4}{|c|}{$+3,+2,+6,+5$} \\
\hline & 4 & \multicolumn{4}{|c|}{$+7,+9,+1,+3$} & \multicolumn{4}{|c|}{$+4,+6,+7,+9$} & \multicolumn{4}{|c|}{$+1,+3,+4,+6$} \\
\hline & 5 & \multicolumn{4}{|c|}{$+8,+7,+2,+1$} & \multicolumn{4}{|c|}{$+5,+4,+8,+7$} & \multicolumn{4}{|c|}{$+2,+1,+5,+4$} \\
\hline & 6 & \multicolumn{4}{|c|}{$+9,+8,+3,+2$} & \multicolumn{4}{|c|}{$+6,+5,+9,+8$} & \multicolumn{4}{|c|}{$+3,+2,+6,+5$} \\
\hline \multicolumn{2}{|c|}{ Times } & $\mathrm{t}_{\mathrm{x} 1}$ & $t_{x 2}$ & $\mathrm{t}_{\mathrm{y} 1}$ & $\mathrm{t}_{\mathrm{y} 2}$ & $t_{x 1}$ & $\mathrm{t}_{\mathrm{x} 2}$ & $\mathrm{t}_{\mathrm{y} 1}$ & $\mathrm{t}_{\mathrm{y} 2}$ & $t_{x 1}$ & $t_{x 2}$ & $\mathrm{t}_{\mathrm{y} 1}$ & \\
\hline
\end{tabular}

From above analysis, the matrix converter is able to generate a desired voltage with required amplitude and phase angle using the direct SVM method. Therefore, the matrix converter's output voltage can be injected into the transmission line to achieve the demanded active and reactive power control goals. In the next section, PID controllers will be derived based on the model of the transmission line, and then combined with SVM to regulate the active and reactive power flowing through the transmission line.

\section{Power Flow Controller}

\subsection{Model Description}

A simulation case study for the MC-UPFC was given in Fig. 11 previously. A mathematical model of the transmission line $X$ can be described by

$$
\frac{d I_{x}}{d t}=\frac{V_{s x}+V_{c x}-V_{r x}}{L}-\frac{R}{L} I_{x}
$$


where $x=a, b, c$ is the index of the three phases. Using the rotating $\mathrm{d}$-q reference frame transformation, the three-phase quantities can be represented in the d-q frame as

$$
\begin{aligned}
& \frac{d I_{d}}{d t}=-\frac{R}{L} I_{d}-\omega I_{q}+\frac{V_{s d}+V_{c d}-V_{r d}}{L} \\
& \frac{d I_{q}}{d t}=-\frac{R}{L} I_{q}+\omega I_{d}+\frac{V_{s q}+V_{c q}-V_{r q}}{L}
\end{aligned}
$$

As we can see from equations (18) and (19), the d and q components are coupled to each other and this will cause coupling effects in the system. The Laplace transforms for (18) and (19) are

$$
\begin{aligned}
& V_{c d}=(L s+R) I_{d}+L \omega I_{q}-V_{s d}+V_{r d} \\
& V_{c q}=(L s+R) I_{q}-L \omega I_{d}-V_{s q}+V_{r q}
\end{aligned}
$$

If the reference frame is synchronized with the source voltage, then $V_{s q}=0$ and the active and reactive power through the transmission line can be expressed as

$$
P=\frac{3}{2} V_{s d} I_{d}, \text { and } Q=-\frac{3}{2} V_{s d} I_{q}
$$

Consequently, $I_{d}$ and $I_{q}$ references corresponding to the $P$ and $Q$ references are obtained as follows:

$$
I_{d}=\frac{2}{3} \frac{P}{V_{s d}}, \text { and } I_{q}=-\frac{2}{3} \frac{Q}{V_{s d}}
$$

\subsection{Controller Design}

In order to design the PID controllers for the power flow control purpose, the $\mathrm{d}$ and q component references for the line current are obtained from the required active and reactive power using (22) and (23). These current references are passed through the PID controllers (shown in Fig. 14) to deliver d and q component references for the series voltage generation. These two references can be converted into threephase quantities, and then direct SVM utilizes these references to provide the derived voltages for the matrix converter. In order to address the $\mathrm{d}$-q coupling effects, the $\mathrm{d}$ and $\mathrm{q}$ components are introduced to the each PID controller with coefficients $k_{1}$ and $k_{2}$. In a similar manner to parameter selection in a PID controller, the selection of these two coefficients is based on empirical methods. As a result, the d-q coupling suppressed 
PID controllers are shown in Fig. 14. As can be seen, the proposed controller is simple and only two PID controllers are required. A Phase Locked Loop (PLL) is used to detect the ramp for the frame transformation.

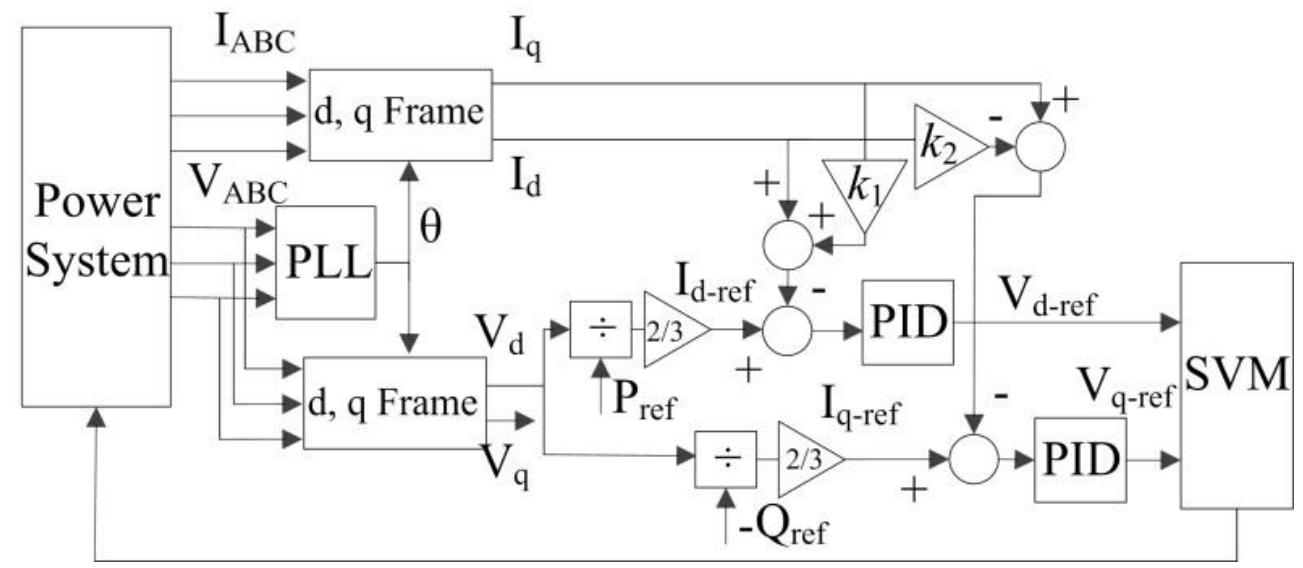

Fig. 14. D-q coupling PID controllers for MC-UPFC

\section{Simulation and Results}

The simulation study is implemented for the $11 \mathrm{kV}$ double-circuit transmission system shown in Fig. 11. The system parameters and controller parameters are given in Tables 4 and 5 respectively. The PID parameters used are consistent throughout the whole simulation work, but they may need to be adjusted for different system ratings and load conditions. All simulations results are shown in per unit (p.u.) values and the base values can be found in Table 4. Small RLC filters are normally necessary at the input terminals of the matrix converter to filter high-frequency harmonics content in the current waveform. The maximum available voltage provided by the MC-UPFC is set to 0.24 p.u. and inherent transmission angle of the system is $15^{\circ}$.

Table 4 System parameters for the simulated transmission system

\begin{tabular}{ccccccc}
\hline $\begin{array}{c}S_{\text {base }} \\
(\mathrm{MVA})\end{array}$ & $V_{\text {base }}(\mathrm{V})$ & $V_{s}$ (p.u.) & $f(\mathrm{~Hz})$ & $V_{r}$ (p.u.) & $X$ (p.u.) & $X_{l}(\Omega)$ \\
\hline 10 & $11 \mathrm{k}$ & 1 & 60 & $0.9659-$ & $0.1102+\mathrm{j} 0.5193$ & $0.0207+0.1947$ \\
\hline
\end{tabular}

Table 5 Parameters of the PID power low controllers

\begin{tabular}{cccccccc}
\hline $\mathrm{k}_{\mathrm{p} 1}$ & $\mathrm{k}_{\mathrm{i} 1}$ & $\mathrm{k}_{\mathrm{d} 1}$ & $\mathrm{k}_{\mathrm{p} 2}$ & $\mathrm{k}_{\mathrm{i} 2}$ & $\mathrm{k}_{\mathrm{d} 2}$ & $\mathrm{k}_{1}$ & $\mathrm{k}_{2}$ \\
\hline 3 & 0.03 & 0 & 11 & 0.06 & 0.05 & 0.09 & 0.001 \\
\hline
\end{tabular}

Fig. 15 shows the active and reactive power contributed by the MC-UPFC due to series voltage compensation. As mentioned earlier, the other contribution to the power compensation is from the line 
current. Therefore, the total available active and reactive power ranges at the sending end are obtained and shown in Fig. 16. In this case, with above given parameters, it is concluded that the approximate active and reactive power ranges from 0 to 4 p.u. and -2 to 2 p.u. respectively, which can be verified by (3).

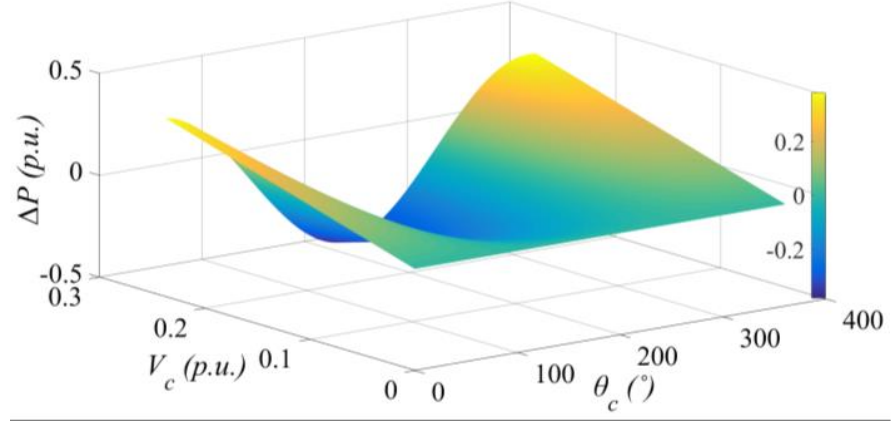

(a)

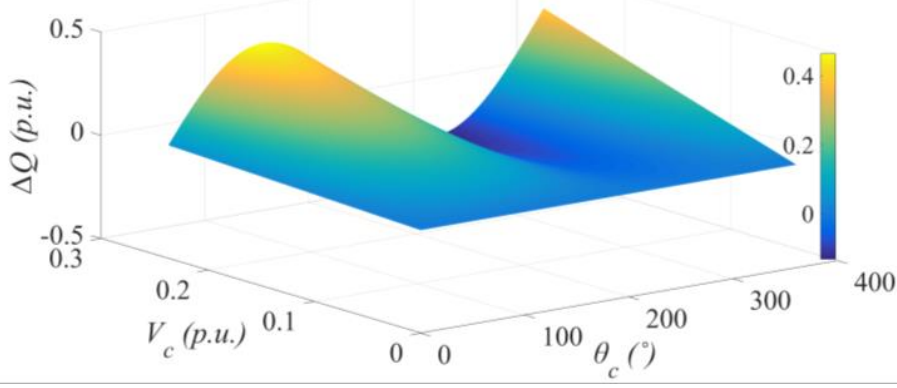

(b)

Fig. 15. Power diagrams as a result of voltage contribution (a) active power and (b) reactive power

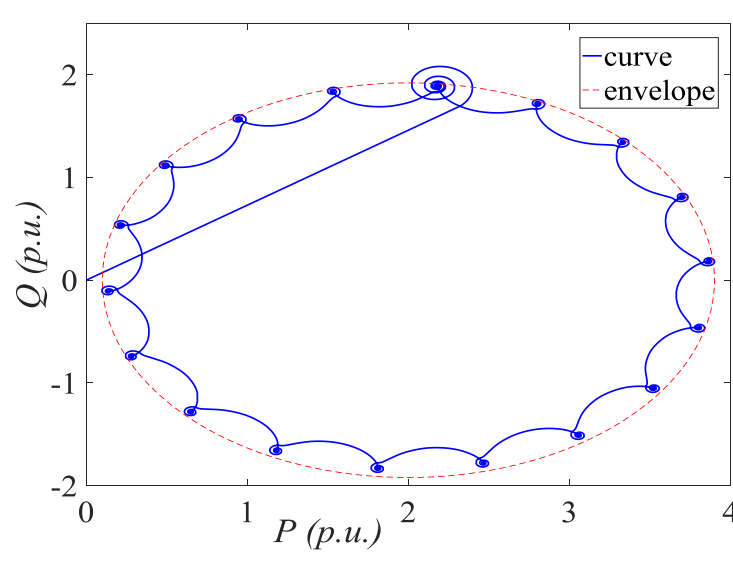

(a)
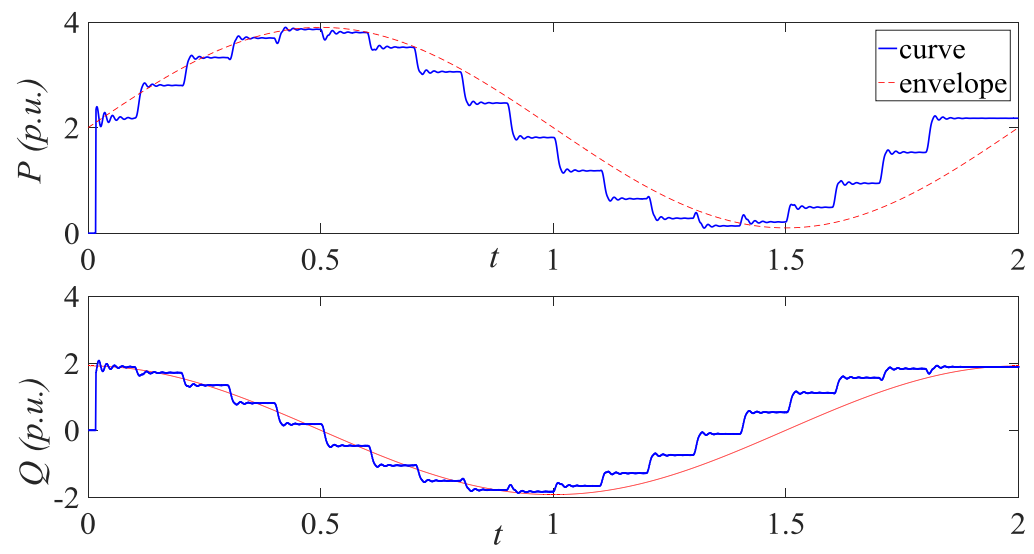

(b)

Fig. 16. Sending-end power ranges with the compensation of MC-UPFC (a) active power and (b) reactive power
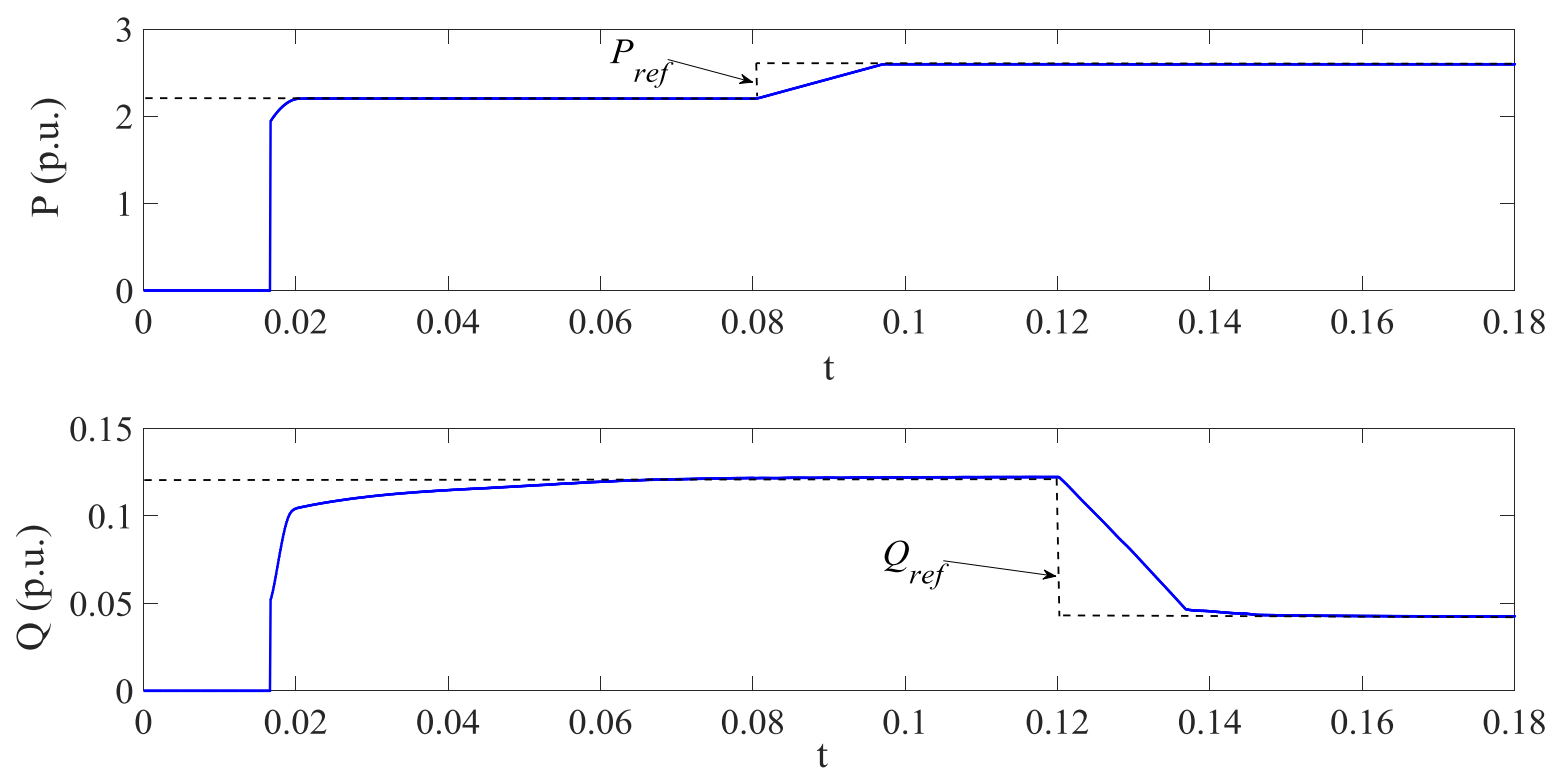

Fig. 17. Response of the sending-end power to the step change in active and reactive power 
Fig. 17 shows the active and reactive power flowing through the line at the sending end. The active power reference is set as 2.2 p.u. before $0.08 \mathrm{~s}$ and 2.6 p.u. after $0.08 \mathrm{~s}$, while the reactive power reference is set as $0.12 \mathrm{p} . \mathrm{u}$. before $0.12 \mathrm{~s}$ and 0.04 p.u. after $0.12 \mathrm{~s}$. As observed from the figures, the output can be regulated to follow the references effectively, and the $\mathrm{d}-\mathrm{q}$ coupling effects are suppressed. $\mathrm{d}$ and $\mathrm{q}$ components of the compensated bus current react in accordance with the power demand are shown in Figs. 18. Fig. 19 shows the sending-end currents of transmission line $X$ and matrix converter output. Fig. 20 shows the injected voltages and equivalent sending-end voltages where the relationship of $V_{L}=V_{s}+V_{c}$ holds as described in (3). The voltages and currents of the supply source 1 are shown in Fig. 21 , and the Total Harmonic Distortion (THD) analysis for the line $X$ current is illustrated in Fig. 22. It can be seen from the simulation results that the proposed controllers are effective in controlling transmission power and improving the transfer capacity of the transmission system. The flexibility of the transmission system is enhanced.
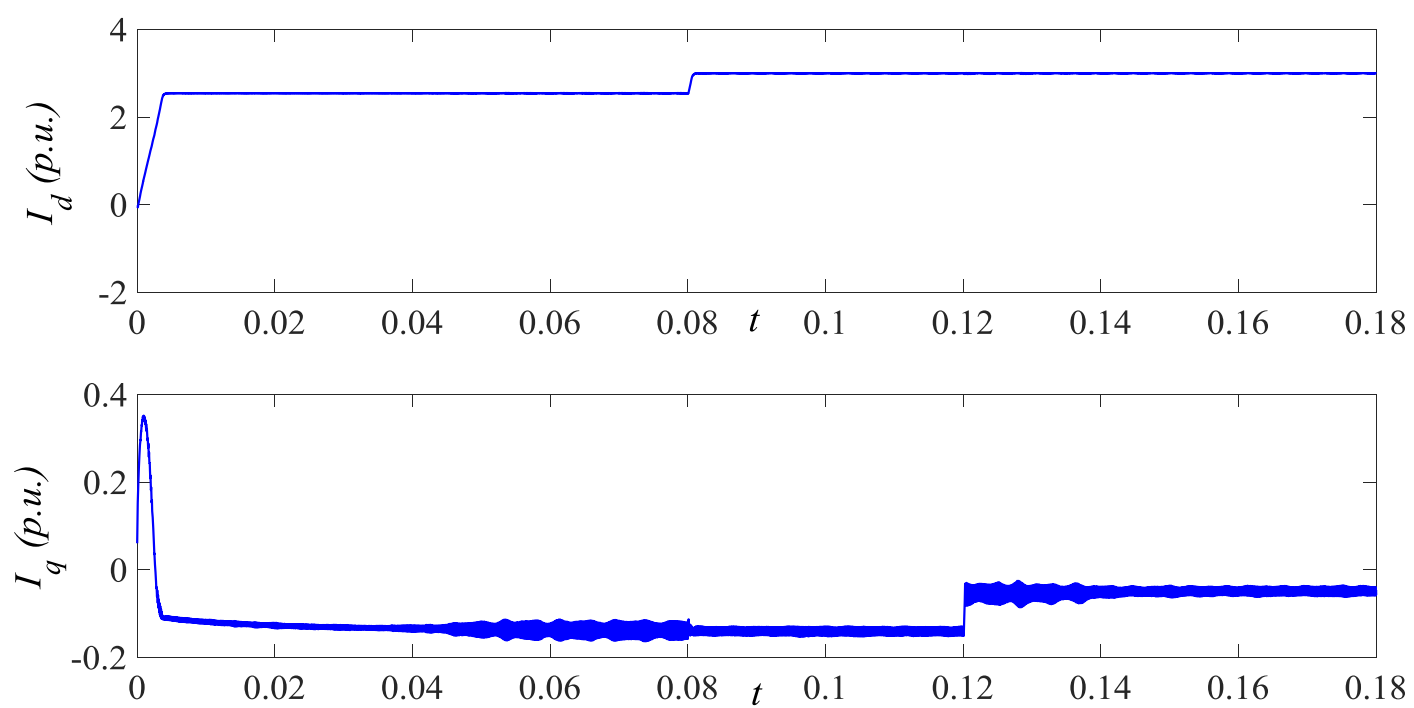

Fig. 18. Line current $d$ and $q$ components reactions to the power changes 

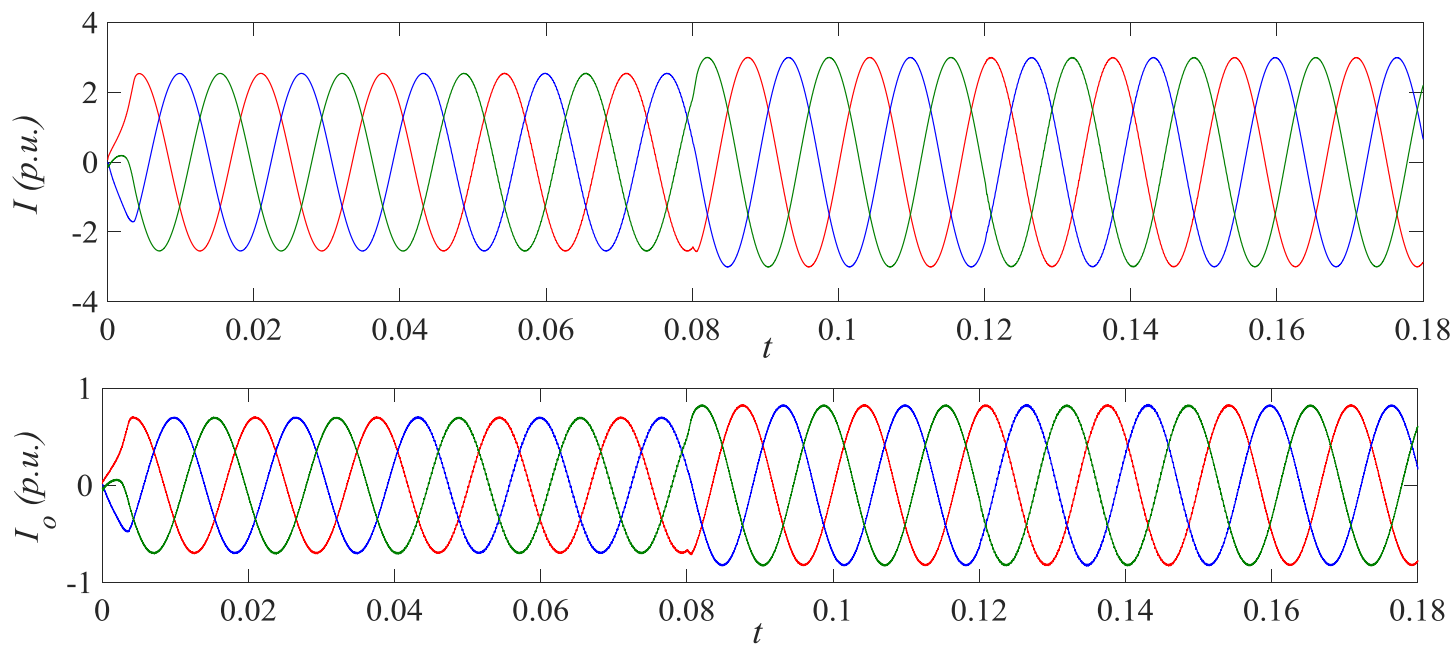

Fig. 19. Transmission line sending-end currents and matrix converter output currents
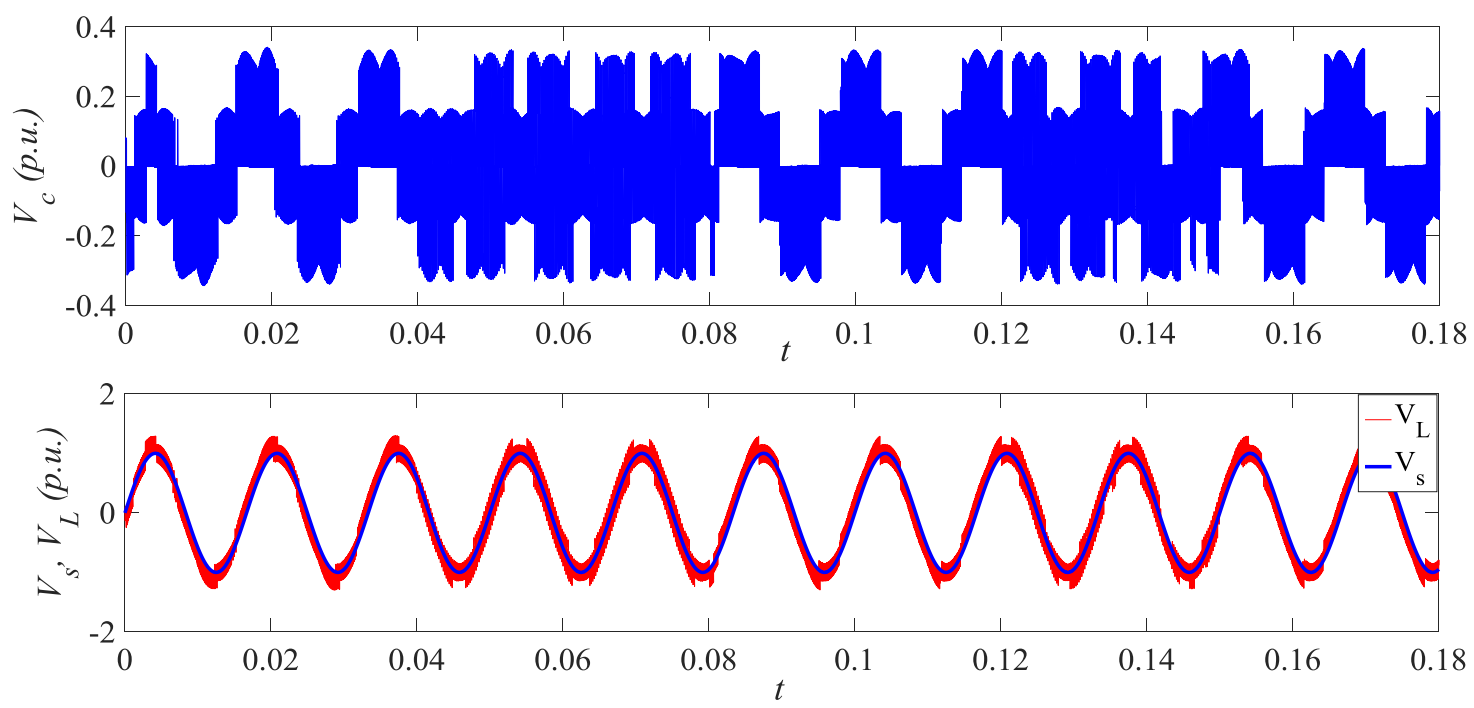

Fig. 20. Injected phase voltage $V_{c}$ by MC-UPFC and equivalent sending-end voltage $\left(V_{L}=V_{s}+V_{c}\right)$
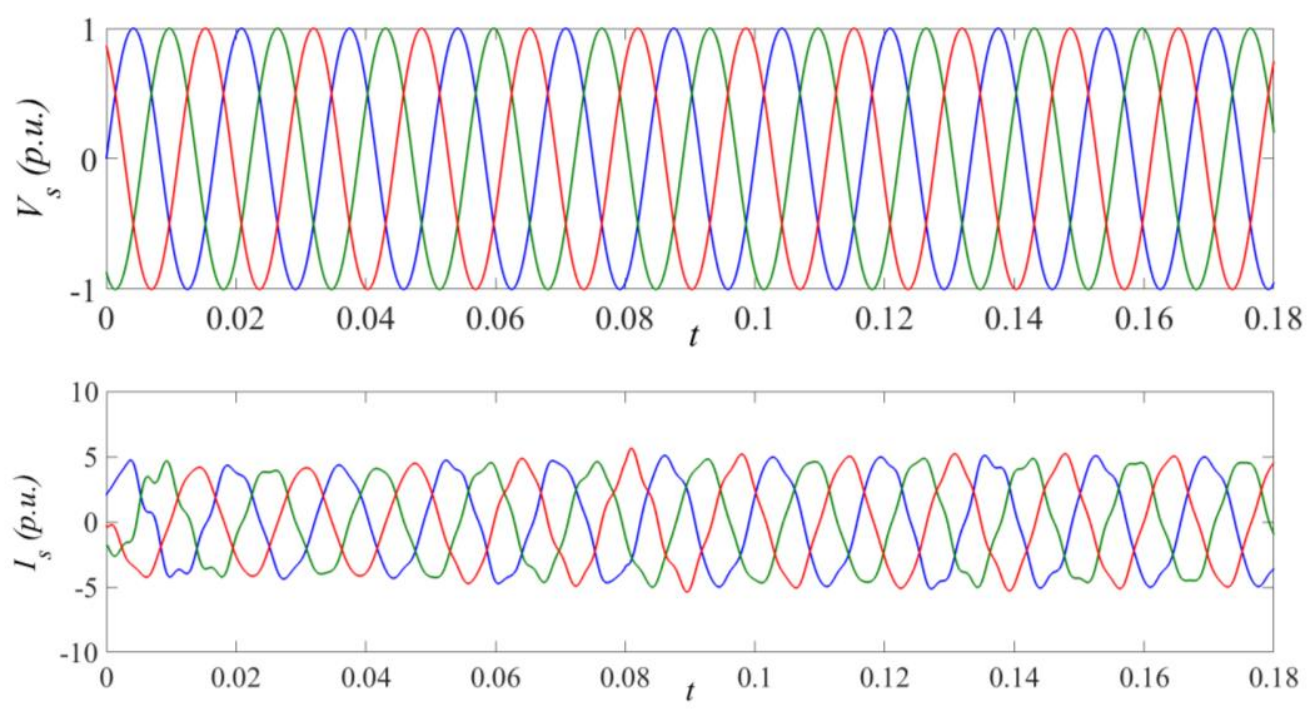

Fig. 21. Three-phase voltages and currents of the supply source 1 


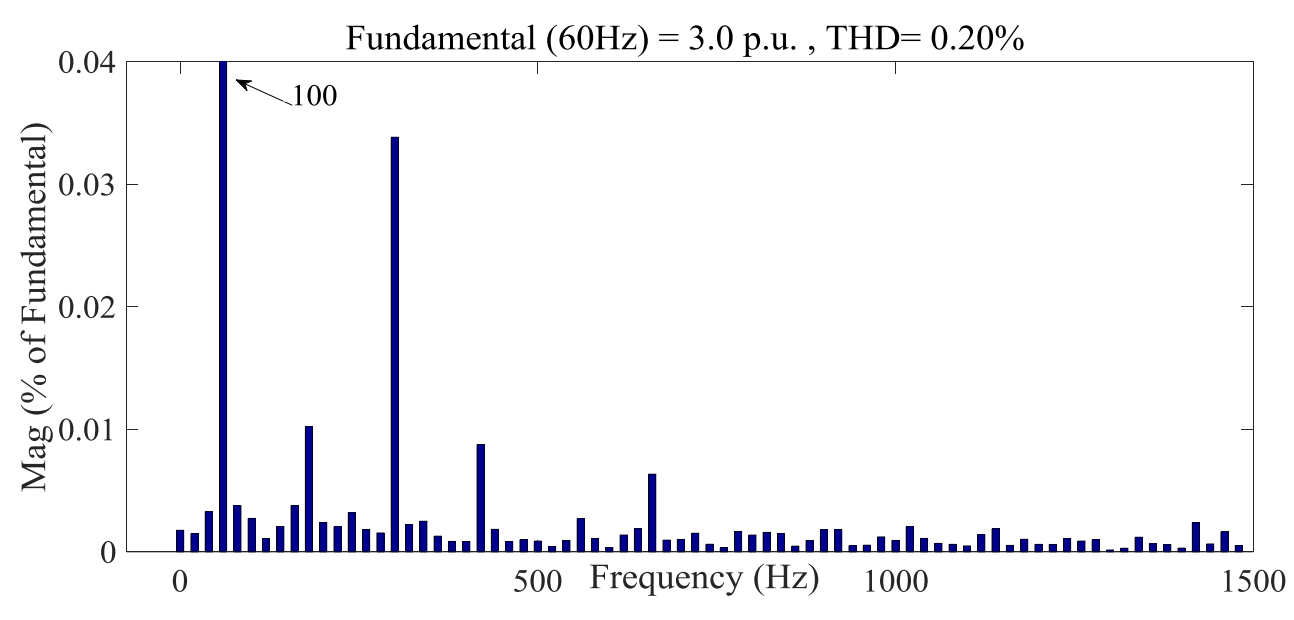

Fig. 22. Current spectrum analysis of the transmission line $X$

\section{Conclusions}

The UPFC is an essential component in a transmission system. The bulky energy storage element in the traditional UPFC increases the volume and weight, reduces the lifetime of the device, and decreases the efficiency. The matrix converter has been proposed as a potential alternative to the back-to-back converter in various applications including UPFC. In this paper, the fully controllable regions of the transmission system without and with the MC-UPFC are analyzed, and the contribution of the MC-UPFC to power controllability is investigated. Then effective and simple PID controllers are developed involving SVM for controlling power flow in a transmission system. Direct SVM and decoupling control of the MC-UPFC are detailed, and decoupling effects are suppressed. This paper presents a design procedure for the closed-loop controller in a MC-UPFC. The MC-UPFC is proved able to provide good flexibility in terms of controlling active and reactive power and increasing the power transfer capability. The proposed controller can follow the references effectively with good dynamics. The steady state errors are negligible. The simulation results validate the effectiveness and feasibility of the proposed scheme and controllers.

\section{References}

[1] Xie, H., Song, Y. H., Yokoyama, A. and Goto, M., "Integrated linear and nonlinear control of unified power flow controllers for enhancing power system stability," Elec. Power Compon. Syst., vol. 31, no. 4, pp. 335-347, 2003.

[2] Singh, S. P., "Congestion mitigation using UPFC," IET Generation, Transmission \& Distribution, vol. 10, no. 10, pp. 2433-2442, 2016. 
[3] Gyugyi, L., "Unified power-flow control concept for flexible AC transmission systems," IEE proceedings C (generation, transmission and distribution), vol. 139, no. 4, pp. 323-331, 1992.

[4] Verveckken, J., Silva, F., Barros, D. and Driesen, J., "Direct power control of series converter of unified powerflow controller with three-level neutral point clamped converter," IEEE Trans. Power Del., vol. 27, no. 4, pp. 17721782, 2012.

[5] Al-Awami Ali, T., Abdel-Magid, Y. L. and Abido, M. A., "Simultaneous stabilization of power system using UPFC-based controllers," Elec. Power Compon. Syst., vol. 34, no. 9, pp. 941-959, 2006.

[6] Hingorani, N. G. and Gyugyi, L., "Combined compensators: unified power flow controller (UPFC) and interline power flow controller (IPFC) ", in: Understanding FACTS: concepts and technology of flexible AC transmission systems, Wiley-IEEE press, pp. 297-352, 2000.

[7] Reddy, M., Balasubba, Y., Obulesh, P., Sivanagaraju, S. and Suresh, C. V., "Mathematical modelling and analysis of generalised interline power flow controller: an effect of converter location," J. Experimental \& Theoretical Artificial Intelligence, vol. 28, no. 4, pp. 655-671, 2016.

[8] Ali Al-Mawsawi, S., "Optimal Location of UPFC Applied to Nonlinear Load Model," Elec. Power Compon. Syst., vol. 32 , no. 1 , pp. 1-12, 2004

[9] Tripathy, L. N., Samantaray, S. R. and Dash, P. K., "A fast time-frequency transform based differential relaying scheme for UPFC based double-circuit transmission line," Int. J. Electr. Power Energy Syst., vol. 77, pp. 404-417, 2016.

[10] Peng, F. Z., Liu, Y., Yang, S., Zhang, S., Gunasekaran, D. and Karki, U., "Transformer-Less Unified PowerFlow Controller Using the Cascade Multilevel Inverter," IEEE Trans. Power Electron., vol. 31, no. 8, pp. 5461-5472, 2016.

[11] Yang, S., Liu, Y., Wang, X., Gunasekaran, D., Karki, U. and Peng, F. Z., "Modulation and Control of Transformerless UPFC," IEEE Trans. Power Electron., vol. 31, no. 2, pp. 1050-1063, 2016.

[12] Monteiro, J., Fernando Silva, J. and Pinto, S., "Matrix converter as unified power flow controller: design and implementation of decoupled direct power controllers," 9th Int. Conf. Compatibility Power Electron. (CPE), Lisbon, Portugal, pp. 197-201, June 2015.

[13] Zhang, J., Dorrell, D. and Li, L., "Applications of the Direct Space Vector Modulation Controlled Matrix Converter as the Unified Power Flow Controller," 8th Int. conf. power electron. motor drives, Glasgow, UK, , pp. 6 , April 2016.

[14] Zhang, J., Li, L. and Dorrell, D., "DQ Coupling Suppressed PID Controller for the Transmission Line Power Flow Control Using a Matrix Converter," IEEE Ind. Electron. Soc. Annu. Meeting (IECON16), Florence, Italy, pp. $6249-6254$, October 2016.

[15] Alcalá, J., Cárdenas, V., Espinoza, J. and Durán, M., "Investigation on the limitation of the BTB-VSC converter to control the active and reactive power flow," Electr. Power Syst. Res., vol. 143, pp. 149-162, 2017.

[16] Monteiro, J., Silva, J. F., Pinto, S. F. and Palma, J., "Matrix converter-based unified power-flow controllers: Advanced direct power control method," IEEE Trans. Power Del., vol. 26, no. 1, pp. 420-430, 2011.

[17] Geethalakshmi,B. and Dananjayan, P., "Investigation of performance of UPFC without DC link capacitor," Electr. Power Syst. Res., vol. 78, no. 4, pp. 736-746, 2008. 
[18] Wheeler, P. W., Rodriguez, J., Clare, J. C., Empringham, L. and Weinstein, A., "Matrix converters: a technology review," IEEE Trans. Ind. Electron., vol. 49, no. 2, pp. 276-288, 2002.

[19] Hojabri, H., Mokhtari, H. and Chang, L., "Stand Alone Performance of Permanent Magnet Synchronous Wind Power Generator with Current Source Matrix Converter," Elec. Power Compon. Syst., vol. 43, no. 8-10, pp. 10181027, 2015.

[20] Yousefi-Talouki, A., Asghar Gholamian, S., Yousefi-Talouki, M. and Yazdani-Asrami, M., "A new direct power control of doubly-fed induction generator using matrix converter," Australian J. Electrical and Electronics Engineering, vol. 10, no. 3, pp. 307-320, 2013.

[21] Jurado, F., Ortega , M. and Cano, A., "Predictive control of matrix converter-based micro-turbine," Elec. Power Compon. Syst., vol. 36, no. 4, pp. 409-431, 2008.

[22] Cárdenas, R., Peña, R., Wheeler, P., Clare, J. and Juri, C., "Control of a matrix converter for the operation of autonomous systems," Renewable Energy, vol. 43, PP. 343-353, 2012.

[23] Arevalo, S. L., Zanchetta, P., Wheeler, P. W., Trentin, A. and Empringham, L., "Control and implementation of a matrix-converter-based ac ground power-supply unit for aircraft servicing," IEEE Trans. Ind. Electron., vol. 57, no. 6, pp. 2076-2084, 2010.

[24] Yamamoto, E., Kang, J.K. and Krug, H.P., "Development of Matrix Converter for Industrial Applications," Yaskawa White Paper, 2007.

[25] Munzer, M., "EconoMac - the First All In One IGBT Module for Matrix Converters", Drives and Control Conference, Section 3, London, 2001.

[26] Itoh, J., Odaka, A. and Sato, I., "High efficiency power conversion using a matrix converter." Fuji Electric Review, vol. 50, no. 3, pp. 94-98, 2004.

[27] Strzelecki, R., Noculak, A., Tunia, H., Sozanski, K. and Fedycza, Z., "UPFC with matrix converter," EPE conf., Graz, Austria, pp. 1-9, September 2001.

[28] Dasgupta, A., Tripathy, P. and Sarathi Sensarma, P., "Matrix converter as UPFC for transmission line compensation," 7th Int. Conf. Power Electron., Daegu, Korea, pp. 1050-1055, October 2007.

[29] Huber, L. and Borojevic, D., "Space vector modulator for forced commutated cycloconverters," Ind. Applicat. Soc. Annu. Meeting Conf. Rec., pp. 871-876, October 1989.

[30] Zhang, S., Guo, R. and Li, K., "Modeling and design of matrix converter based unified power flow controller with implementation of complex vector synchronous frame PI current regulators," Int. Conf. Electrical Machines and Systems (ICEMS), Busan, Korea, pp. 1619-1623, October 2013.

[31] Round, S. D., Yu, Q., Norum, L. E. and Undeland, T. M., "Performance of a unified power flow controller using a dq control system," 6th Int. Conf. AC and DC Power Transmission, pp. 357-362, April 1996.

[32] Kolar, J. W., Friedli, T., Rodriguez, J. and Wheeler, P. W., "Review of three-phase PWM AC-AC converter topologies, " IEEE Trans. Ind. Electron., vol. 58, no.11, pp. 4988-5006, 2011.

[33] Kouro, S., Cortés, P., Vargas, R., Ammann, U. and Rodríguez, J., "Model predictive control—A simple and powerful method to control power converters," IEEE Trans. Ind. Electron, vol. 56, no. 6, pp. 1826-18386, 2009.

[34] Prasad, V. H., "Analysis and Comparison of Space Vector Modulation schemes for Three-Leg and Four-Leg Voltage Source inverters," Master Thesis, Virginia Polytechnic Institute and State University, 1997. 